\section{onis}

OAK RIDGE

NATIONAL

LABORATORY

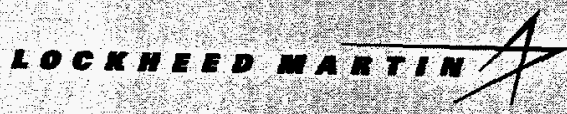

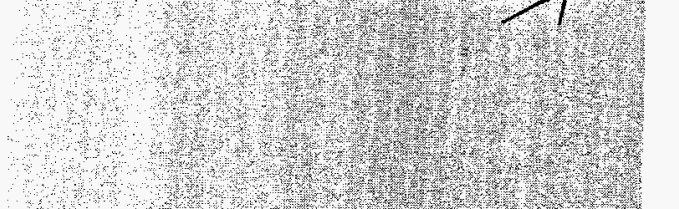

度

14
CRADA Final Re Ort for

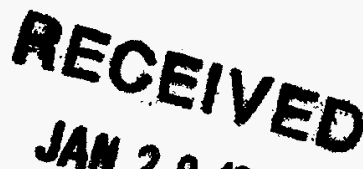
JAN 281989

CRADA Number 93-0195

MODIFICATION AND VALIDATION OF AN AUTOMOTIVE DATA PROCESSING UNIT, COMPRESSED VIDEO SYSTEM, AND COMMUNICATIONS EQUIPMENT

Richard J. Carter

Oak Ridge National Laboratory

Prepared by the

Oak Ridge National Laboratory

Oak Ridge, Tennessee 37831

ORNL is managed by

Lockheed Martin Energy Research Corp.

for the U. S. Department of Energy

under Contract No. DE-AC05-96OR22464

Approved for public release; distribution is unlimited 


\section{DISCLAIMER}

This report was prepared as an account of work sponsored by an agency of the United States Government. Neither the United States Government nor any agency thereof, nor any of their employees, make any warranty, express or implied, or assumes any legal liability or responsibility for the accuracy, completeness, or usefulness of any information, apparatus, product, or process disclosed, or represents that its use would not infringe privately owned rights. Reference herein to any specific commercial product, process, or service by trade name, trademark, manufacturer, or otherwise does not necessarily constitute or imply its endorsement, recommendation, or favoring by the United States Government or any agency thereof. The views and opinions of authors expressed herein do not necessarily state or reflect those of the United States Government or any agency thereof. 


\section{DISCLAIMER}

Portions of this document may be illegible in electronic image products. Images are produced from the best available original document. 


\title{
MODIFICATION AND VALIDATION OF AN AUTOMOTIVE DATA PROCESSING UNIT, COMPRESSED VIDEO SYSTEM, AND COMMUNICATIONS EQUIPMENT
}

Cooperative Research and Development Agreement

Number ORNL93-0195

Final Report

\author{
Richard J. Carter \\ Cognitive Systems and Human Factors Group \\ Intelligent Systems Section \\ Computer Science and Mathematics Division \\ Oak Ridge National Laboratory
}

Donald R. Brady

Signal Processing Systems

Instrumentation Group

Scientific Atlanta, Incorporated

13112 Evening Creek Drive, South

San Diego, CA 


\section{Purpose of the Cooperative Research and Development Agreement}

The primary purpose of the "modification and validation of an automotive data processing unit (DPU), compressed video system, and communications equipment" cooperative research and development agreement (CRADA) was to modify and validate both hardware and software, developed by Scientific Atlanta, Incorporated (S-A) for defense applications (e.g., rotary-wing airplanes), for the commercial sector/surface transportation domain (i.e., automobiles and trucks). S-A also furnished a state-of-the-art compressed video digital storage and retrieval system (CVDSRS), and off-the-shelf data storage and transmission equipment to support the data acquisition system for crash avoidance research (DASCAR) project conducted by Oak Ridge National Laboratory (ORNL). In turn, $S-A$ received access to hardware and technology related to DASCAR.

\section{Data Acquisition System for Crash Avoidance Research}

DASCAR was designed for the National Highway Traffic Safety Administration's (NHTSA) Office of Crash Avoidance Research. The primary objective of the project was to develop a portable DASCAR that will allow driver performance data to be collected using a large variety of vehicle types and that would be capable of being installed on a given vehicle type within a relatively short-time frame. DASCAR was designed and implemented in two phases. During phase I a feasibility study for designing and fabricating DASCAR was conducted. Human factors research needs were evaluated, and existing methods, measures, techniques, hardware, and software for evaluating the driver/vehicle/environment were identified. In the second phase of the program, DASCAR was actually developed, constructed, and validated. The development effort for DASCAR was driven by a number of requirements which are briefly described below.

Parameters and Measures. The data acquisition system is capable of collecting and analyzing driver-related, vehicular, and environment parameters and measures. Driver-related variables consist of driver control actions, equipment status, and physiological measures. Parameters that are currently recorded by DASCAR are exhibited in Table 1. A few of the environment parameters are sensor derived; most of them are however video derived. The data acquisition system can collect other variables if a researcher so desires. All that would have to be done would be to add additional sensors.

Off-the-Shelf and State-of-the-Art. The data acquisition system consists of both off-the-shelf hardware and software, and state-of-the-art technology. ORNL procured most of the system required equipment. The hardware was subsequently modified as appropriate for DASCAR application. Some of the hardware and software had to be designed and developed from scratch.

Portability. The data acquisition system is portable. It can be installed in a particular vehicle quickly and can rapidly be removed and placed within another vehicle. It takes between one and two weeks to install the complete DASCAR within a new automobile or truck, depending on the vehicle type and configuration. 
Table 1. Parameters Currently Collected by DASCAR

\section{Driver Parameters}

Driver Control Actions

Acceleratorithrottle

Brake pedal

Steering wheel

Time between accelerator release and brake application (derived)

Equipment Status

Auxiliary device (e.g., side-object detection)

Brake lights

Hazard flashers

Headlights

Horn

Parking lights

Rear window defogger

Rear window wiper

Seat beits

Turn signals

Windshield wipers

Phỵsiological Parameters

Core temperature

Electrocardiogram

Electroencephalogram

Electromyogram

Electrooculogram

Fidget index

Galvanic skin response

Respiration

Skin temperature

Vehicle Parameters

Distance traveled (derived)

Elapsed time (derived)

Forward velocity (derived)

Heading

Headway

Lateral acceleration

Lateral lane keeping

Longitudinal acceleration

Pitch

Rol]

Tailway

Time-to-collision (derived)

Vehicle location

Vertical acceleration

Yaw

Environment Parameters

Sensor Derived

Illumination

Lumination

Noise/sound 


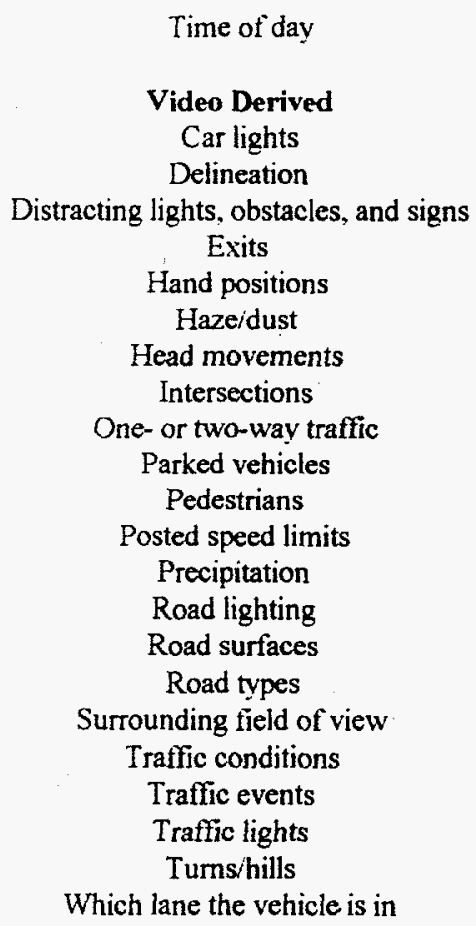

Automobiles and Trucks. The DASCAR was designed so that it can be positioned within virtually any passenger vehicle. It can be installed within a wide range of vehicle types (compact, intermediate, and large automobiles, minivans, and small, mid-size, and large trucks) built by the three United States (U.S.) domestic vendors (General Motors, Ford, and Chrysler).

Unobtrusiveness and Inconspicuousness. The data acquisition system is both unobtrusive to the driver and inconspicuous to the outside world. Placement of hardware within a vehicle does not obstruct the driver's primary task of driving. Instrumentation, cables, and wires connecting different pieces of the system are hidden, well out of the view of the driver. Antennas, sensors, and cameras are situated on the exterior of the vehicle so that they cannot be seen by other drivers. As far as possible, the vehicle looks and drives like any other vehicle on the road.

Modularity and Flexibility. The DASCAR was modularly designed; that is to say, the system permits installation of only those data collection capabilities required for a particular study. An individual does not have to instrument the vehicle with the entire system in order to collect or record a subset of parameters. The data acquisition system was designed so that it has the flexibility to accommodate new data acquisition and sensor technologies as the state-of-the-art changes.

Three Modes of Data Collection. The DASCAR has three modes of data collection. The first consists of recording parameter data onboard the vehicle via a laptop computer. This mode provides a backup capability in the case of radio-link failure or signal corruption during data transmission. The second mode comprises radio telemetry. The radio telemetry link is used to 
transmit data from the vehicle to a base station during use at a test track. The third includes cellular telephone equipment. This technology is employed to transmit data from a vehicle in an open-road situation, anywhere in the U.S., to a base station that may be located a few, to many hundreds of, kilometers away.

Extended Periods of Recording Data and Cost. The DASCAR collects parameter data over two extremes of time - from as little as 20 minutes to as much as six months. The data acquisition system was designed with cost as a main consideration. Technical capabilities - cost tradeoff analyses were performed for each part of DASCAR.

\section{DASCAR Components}

The DASCAR consists of seven components: a data acquisition platform, a data storage and transmission system, a power system, an equipment status bus (ESB), a sensor suite, a video data system, and a central data collection/analysis facility (CDC/AF). The hardware and software which were modified and furnished by S-A was included as part of the DASCAR prototype delivered to NHTSA. The S-A supplied equipment consists of microprocessor-based hardware to perform signal conditioning, execution of data storage, and communication via multimedia.

Data Acquisition Platform and Data Storage and Transmission System. The data acquisition platform is used to capture and process signals from the various sensors installed within and around the vehicle. The data storage and transmission system is composed of several components: cellular telephone equipment, radio telemetry, satellite transmission equipment, a laptop computer, docking station, and a small computer system interface (SCSI) two hard drive. The system is utilized to receive, assemble, transmit, store, integrate, analyze, evaluate, and interpret the parameter data collected via the DASCAR sensor suite.

Power System. The DASCAR power supply consists of three main components: electronic isolation from the vehicle electrical system, sealed lead-acid (gel-cell) storage batteries, and a switching precision power supply. The electronic isolation system provides total separation from the vehicle power system when the vehicle is powered down. This capability prevents the data acquisition system from draining the vehicle's battery during power-down, which could preclude the motorist from starting the vehicle. This electronic isolation component prevents fluctuations in the vehicle charging-electrical system from entering the DASCAR power supply when coupled with the gel-cell storage batteries.

The gel-cell storage batteries serve two purposes. First, they serve a power-smoothing function, absorbing any ripples and spikes which may occur as a result of irregularities in the vehicle charging system, and they compensate for lowered voltages which may occur, for example, when the vehicle sits in traffic with the air conditioning going in summer heat. These batteries also provide the power required for volatile memory preservation during power-down of the data acquisition system. The remaining power supply component is a precision direct current 
switching power supply. This component provides the required voltages for the various DASCAR items.

Equipment Status Bus. The ESB is used to monitor the use of auxiliary devices, brake lights, hazard flashers, headlights, horn, parking lights, rear window defogger and wiper, seat belts, turn signals, and windshield wipers.

Sensor Suite. The DASCAR sensor suite comprises transducers, systems, devices, sensors, and meters to gather parameter data from the driver, vehicle, and environment. The sensor suite includes: linear position transducers, a pedal force transducer, an accelerometer, an ambulatory data recording system, a six degrees of freedom orientation sensor, Hall-effect sensors, an electronic compass, range sensors, radiometers/photometers, a sound level meter, a lateralposition lane tracking system, and a global positioning system (GPS) receiver.

The linear position transducers are employed to collect accelerator/throttle and steering wheel data from the vehicle. The pedal force transducer is utilized to record brake pedal application force. The accelerometer is used to collect fidget index data from the vehicle driver. The ambulatory data recording system is employed to collect core temperature, electrocardiogram, electroencephalogram, electromyogram, electrooculogram, galvanic skin response, respiration, and skin temperature data from the driver. The six degrees of freedom orientation sensor is utilized to record acceleration (lateral, longitudinal, and vertical), pitch, row, and yaw data from the vehicle. The Hall-effect sensors are used to collect distance traveled and velocity data from the vehicle. The electronic compass is employed to record heading data from the vehicle. The range sensor is utilized to collect headway, tailway, and time-to-collision data from the vehicle. The radiometers/photometers are used to record illumination and lumination data from the environment outside the vehicle. The sound level meter is employed to collect steady state and impulse noise and sound as heard by the driver inside the vehicle. The lateral-position lane tracking system is utilized to collect lateral lane keeping data from the vehicle. The GPS receiver is used to collect vehicle location and route traveled.

Video Data System. The DASCAR video data system comprises both color and black-and-white video micro cameras, a vertical interval time code (VITC) generator, a digital quad picture processor, a digital picture transmission system, a CVDSRS encoder, and a super VHS recorder. The micro cameras are employed to record video data inside the vehicle and in the outside environment. They consist of camera heads, lenses, pick up devices, and cables. The VITC generator is utilized to time code the video output from the micro cameras and to provide video data synchronization with collected sensor data. The digital quad picture processor is used to display and record images from four video micro cameras at one time. The digital picture transmission system is employed to send high quality color pictures to the CDC/AF in near real time. Both the CVDSRS encoder and super VHS recorder are employed to collect and handle video from the micro cameras installed within and around the vehicle. The CVDSRS encoder digitizes and compresses analog video material in real time. The super VHS recorder must have a 12 volt direct current input. 
Central Data Collection/Analysis Facility. The CDC/AF consists of components that support, analyze, and collect parameter data from the DASCAR prototype. Support systems include: a CVDSRS decoder, radio telemetry hardware, satellite-reception equipment, a digital quad picture processor, a super-VHS recorder, a super-VHS monitor, and a digital picture receiver system. Analysis of the acquired parameter data is facilitated by a personal computer and special supporting software. Collection of the DASCAR sensor and video data at the CDC/AF is handled in several ways: it is received through radio telemetry equipment; it is transferred via satellite equipment; and it is received through cellular/land lines. The $\mathrm{CDC} / \mathrm{AF}$ also contains data storage devices compatible with the DASCAR prototype devices. They are used for archiving information and directly downloading parameter data from the DASCAR prototype.

\section{CRADA Tasks}

The technical objective of the CRADA was to modify and validate data acquisition, storage, retrieval, and communications/transmission hardware and software manufactured by S-A for application to the DASCAR which was designed and developed by ORNL. The work conducted under the CRADA was subdivided into three tasks; each is described below.

Modification of S-A Hardware and Software. The main objective of the first task was to modify the DPU developed by S-A for the Department of Defense for applicability to the data acquisition system constructed by ORNL for NHTSA. This task was performed almost entirely by S-A; ORNL, however, provided background information on DASCAR. S-A modified their DPU, both hardware and software, as appropriate for incorporation within DASCAR. The functionality of the DPU was tailored to individual DASCAR sensor requirements. Sigma delta convertors allowed elimination of most of the analog circuitry, and digital signal processing and use of techniques such as signal averaging allowed for fast, flexible diagnostic performance.

The modified DPU consists of a number of input multiplexers which permit up to 42 analog inputs per board along with four digital inputs. It is capable of high speed analog/digital data acquisition and fast Fourier transform conversion of time domain data to frequency domain data. Each board provides signal conditioning and analog-to-digital conversion, and terminates in a choice of either an RS-232 or RS-422 data bus output. The boards can be mounted in either a single-board case or a multi-board chassis with a passive backplane. The DPU contains four megabytes of flash memory, permitting nonvolatile storage of local data-collection programs and/or data, thus providing the flexibility necessary for changing sensor needs without changing hardware. This flexibility is especially important since DASCAR will be used in a variety of different research settings requiring different sensor suite configurations. In addition, software-based diagnostics can be easily upgraded as sensor technology changes over the life of the DASCAR package. Technical material on S-A's DPU is presented in the appendix.

Delivery and Integration of the S-A Hardware and Software. The major purpose of the second task was to deliver the modified equipment and other S-A hardware and software, and to integrate the equipment into DASCAR. Performance of the task was divided between S-A and 
ORNL. S-A's contribution to the second task was to provide engineering services and a modified DPU to support decentralized data collection of the DASCAR data.

S-A also supplied the following material for the DASCAR prototype: cellular telephone equipment (i.e., a modem, cellular data interface, and a cellular telephone); radio telemetry hardware; satellite transmission equipment; a laptop computer, docking station, and SCSI-2 hard drive; super-VHS recorder; and CVDSRS encoder. In addition, S-A provided cabling for interconnecting the DASCAR sensor suite with the DPU and other S-A provided equipment, and system operation and maintenance manuals.

The cellular telephone system is used to transmit sensor suite data and digital pictures from the vehicle to the $\mathrm{CDC} / \mathrm{AF}$ in near real time, and to receive data back from the facility. The radio telemetry and satellite transmission equipment support short and long-term positional monitoring and data transmission requirements. The radio telemetry is employed to transmit data from the vehicle to a base station during use at a test track. The satellite system produces two-way global data communications and precise GPS position determination. It is utilized during testing under open road conditions. The laptop computer is a 486-based system with a 545-megabyte hard drive. The docking station provides the required ISA slots for the CVDSRS encoder. The SCSItwo hard drive is utilized to assemble and integrate the video data digitized and compressed by the CVDSRS encoder. Brief material on the equipment that S-A provided for the DASCAR prototype is shown in the appendix.

S-A supplied the following hardware and software for the CDC/AF via the CRADA: CVDSRS decoder; radio telemetry; and satellite-reception equipment (i.e., Macintosh II computer, GPS receiver, Inmarsat Standard C transceiver with antenna, and Mapstar software). Mapstar is a graphic display; communications, and database-management systems for vehicle tracking applications. With this software a user is able to track vehicles, send and receive messages, establish data communications, and obtain vehicle status reports. Vehicle locations are displayed on maps, which may be customized to the human's specific requirements, providing an interface for the individual to the map display and two-way communications. Using Mapstar, the CDC/AF is able to monitor in near real time, the location and speed of all vehicles in the fleet, and send and receive messages. Th appendix displays information on the $\mathrm{S}-\mathrm{A}$ hardware and software furnished through the CRADA for the DASCAR CDC/AF.

Once all of the equipment, hardware, and software had been delivered, ORNL tested and evaluated each component of hardware against S-A's specifications and ORNL's own standard of expected performance. The equipment was subsequently installed on an individual basis within an ORNL vehicle. This procedure allowed ORNL to determine the most unobtrusive, inconspicuous, and cost-effective mounting location.

ORNL incorporated and integrated the S-A supplied hardware, software, and equipment with the other DASCAR components. A preliminary "shakedown" of the complete system was then carried out. The DASCAR was examined and evaluated as a complete unit. Sampling rates and 
measured parameters were analyzed to ensure optimal performance and true validity of the acquired data. Once these data were gathered, ORNL adjusted and re-calibrated the system accordingly. DASCAR was subsequently removed completely and installation was repeated a number of times to gain an accurate idea of complete installation, operation, and removal of DASCAR. Upon satisfactory completion of the DASCAR construction and preliminary shakedown, ORNL provided NHTSA with an operational demonstration of DASCAR at their East Liberty, $\mathrm{OH}$ test facility. The demonstration included an on-the-road demonstration of the entire data acquisition system using NHTSA's test track. In addition, the demonstration also consisted of a briefing, containing the following:

- A description of the installation process and portability of the system.

- A description of the sensor technology used and their calibration.

- A description of the parameters measured.

- A description of the video system and its technology.

- A description of the data acquisition/transmission process.

- A description of the data reduction/analysis process.

Installation and Validation of the S-A Hardware and Software. The principal objective of the third task was to install the modified equipment and other S-A furnished hardware and software, along with the other DASCAR components, and validate the whole data acquisition system. This task was performed almost entirely by ORNL; S-A did, however, support installation of their equipment.

ORNL generated a plan for validating the prototype data acquisition system with regard to: removal of DASCAR from an existing vehicle, and installation and calibration in other vehicles; reliability of the sensors and systems; data collection/transmission process (data integrity); impact on the driveability of the vehicle and obtrusiveness of the system to the driver; data analysis procedures; conspicuousness of the vehicle to other drivers; and DASCAR installation and removal training and documentation. In order to identify any operational problems not captured by the systems testing and evaluation, the validation plan also addressed a short-term pilot research program to manipulate DASCAR under operational conditions using "naive" drivers. The effort exercised the full capabilities of the data acquisition system. ORNL subsequently evaluated and pilot tested the data acquisition system using the validation plan. The plan was implemented in full at the NHTSA East Liberty, $\mathrm{OH}$ test facility, and was carried out as a cooperative effort with the Vehicle Research and Test Center staff.

ORNL assessed the time required to remove DASCAR from a vehicle and the time required to install and calibrate the system in other vehicles. Installation and calibration in five other vehicle types were carried out and included:: one compact, one full size vehicle, one minivan, one multipurpose vehicle, and one heavy vehicle. All problems encountered in the installation and removal process were documented. Since DASCAR is intended to be installed on a wide variety of vehicles with different vehicle imposed constraints, it is likely that problems with installation will be highly vehicle specific. For this reason, ORNL sampled (i.e., examined, not installed) at 
least four vehicles in each class, representing a cross section of manufacturers, to identify, to the greatest extent possible, the problems that can be anticipated in installing the data acquisition system.

ORNL determined the reliability of the sensors and systems by exercising DASCAR (installed in a vehicle) under a variety of conditions including: day/night, rain, reduced visibility (e.g., fog), various roadway conditions (e.g., level, hilly, and rough), hot/cold weather, different drivers (driving styles), and different installers/repeated installations. This was used to define: the conditions under which data collection can take place; the installation, and removal practices and constraints that will maximize system/sensor reliability; and the specific limitations of conditions (if any) under which an equipped vehicle can be utilized or of the parameters that can be measured. Since installation and use in different vehicles or types of vehicles may influence system reliability and constraints, reliability was investigated for each vehicle type. For one vehicle type, ORNL evaluated systems reliability over a continuous period of 30 days with particular attention paid to maintenance of calibration and data integrity.

Data were collected under the variety of conditions defined above to determine the integrity of data from the sensors to the point of analysis. Where raw data is transmitted (i.e., not recorded onboard) to the $\mathrm{CDC} / \mathrm{AF}$, ORNL compared raw data collected directly from the sensors and analyzed separately from vehicle systems, with data collected at the data collection point using vehicle systems. This process was performed for all parameters with a sufficiently long datacollection period to be assured of data integrity.

ORNL ensured that the installed DASCAR does not impact the driveability of the vehicle, and specifically does not compromise safety frem the standpoint of vehicle handling and/or visibility. ORNL further made sure that the system is as unobtrusive to the driver of the vehicle as possible. All instances where either the operation of the vehicle or performance of the driver is unavoidably compromised by DASCAR were documented. At no time, however, was the safety of the driver jeopardized.

To ensure that the characteristics, format, and variability of the collected data are compatible with the potential analysis strategies, ORNL exercised the recommended data-analysis procedures for each of the parameters measured. Given the desire to minimize the impact of an instrumented vehicle's appearance on the behavior of other drivers, ORNL assessed the conspicuousness of an instrumented vehicle and how it might influence the behavior of other drivers.

ORNL exercised the training procedures and documentation for installing, calibrating, operating, maintaining, and removing DASCAR to make sure that individuals not involved with the development and construction of the data acquisition system could successfully conduct the necessary activities. 
APPENDIX 


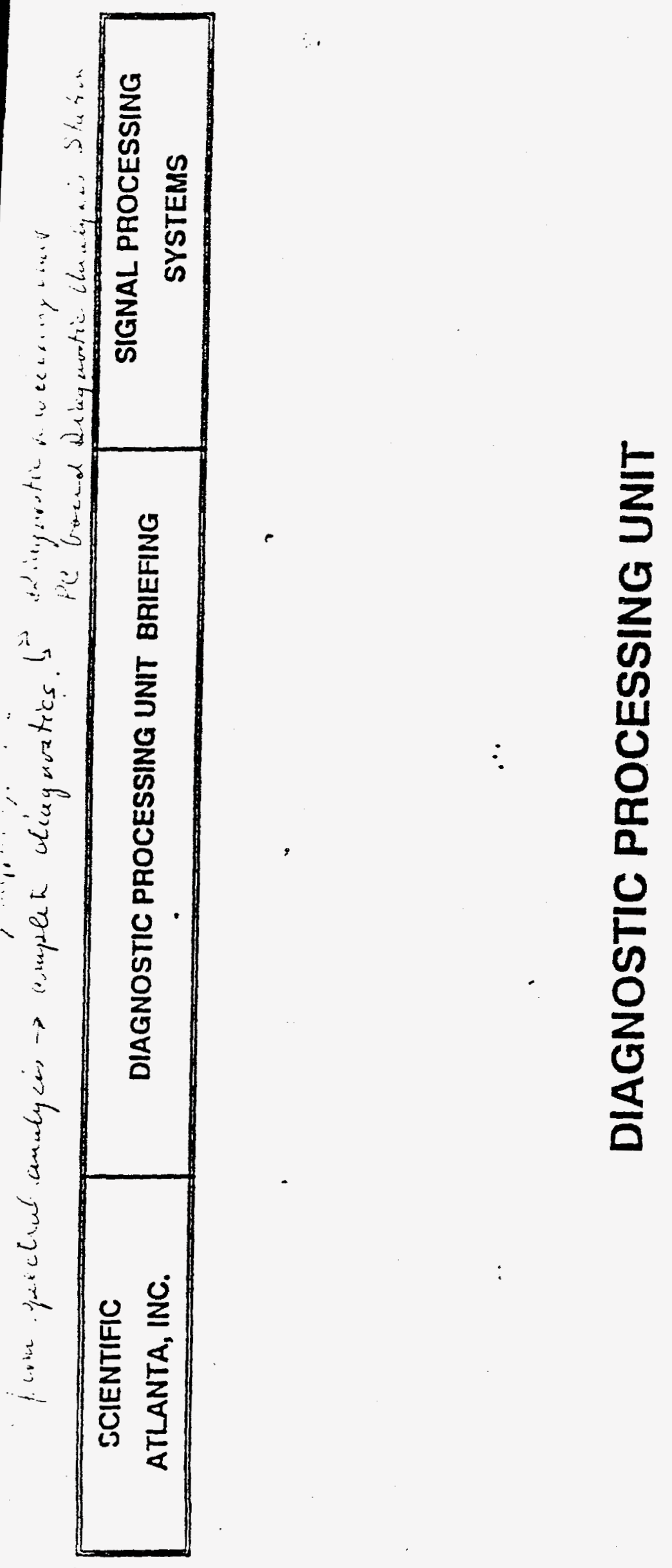

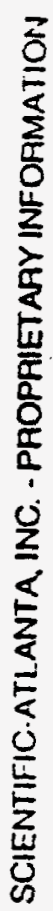



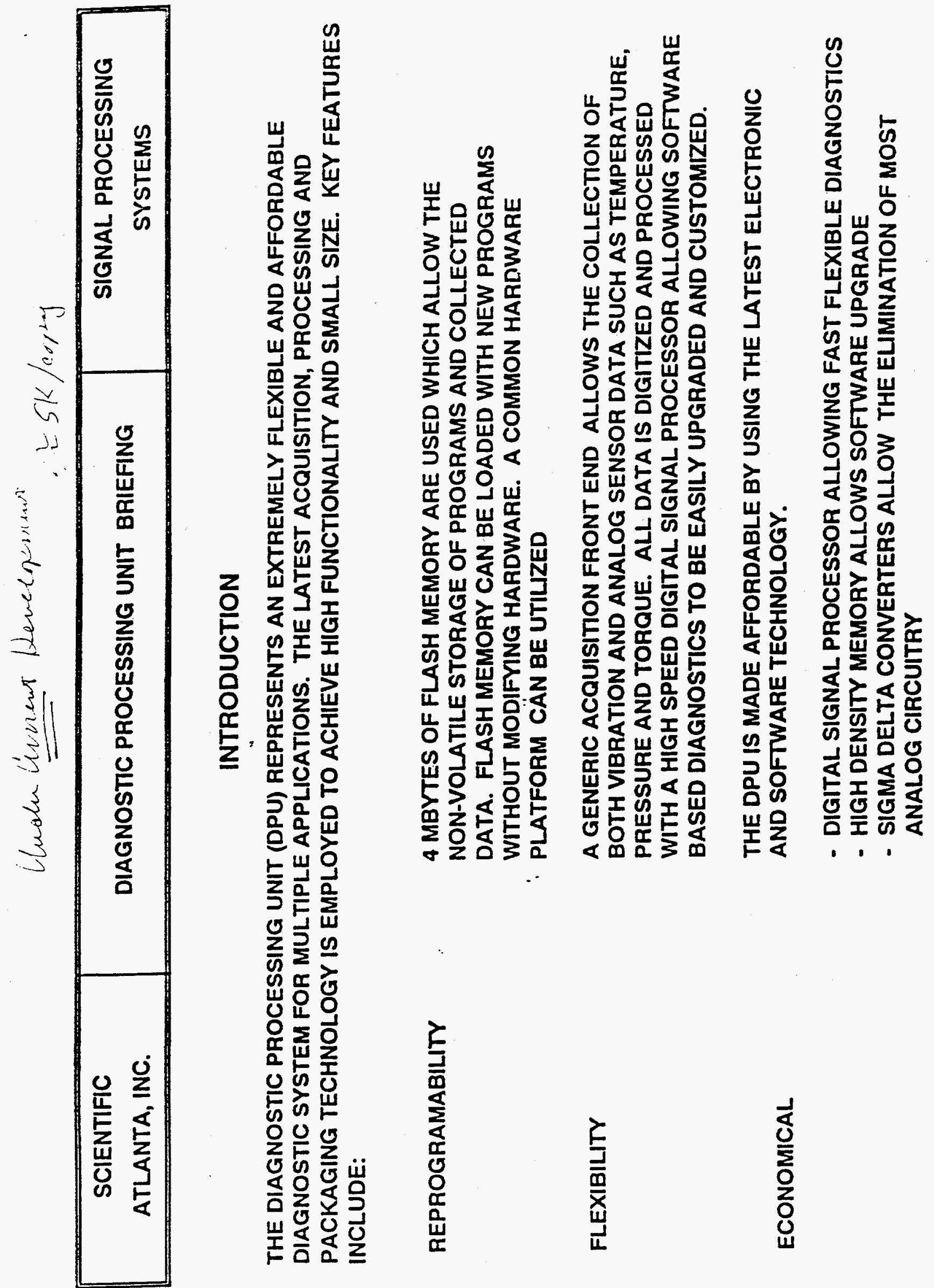


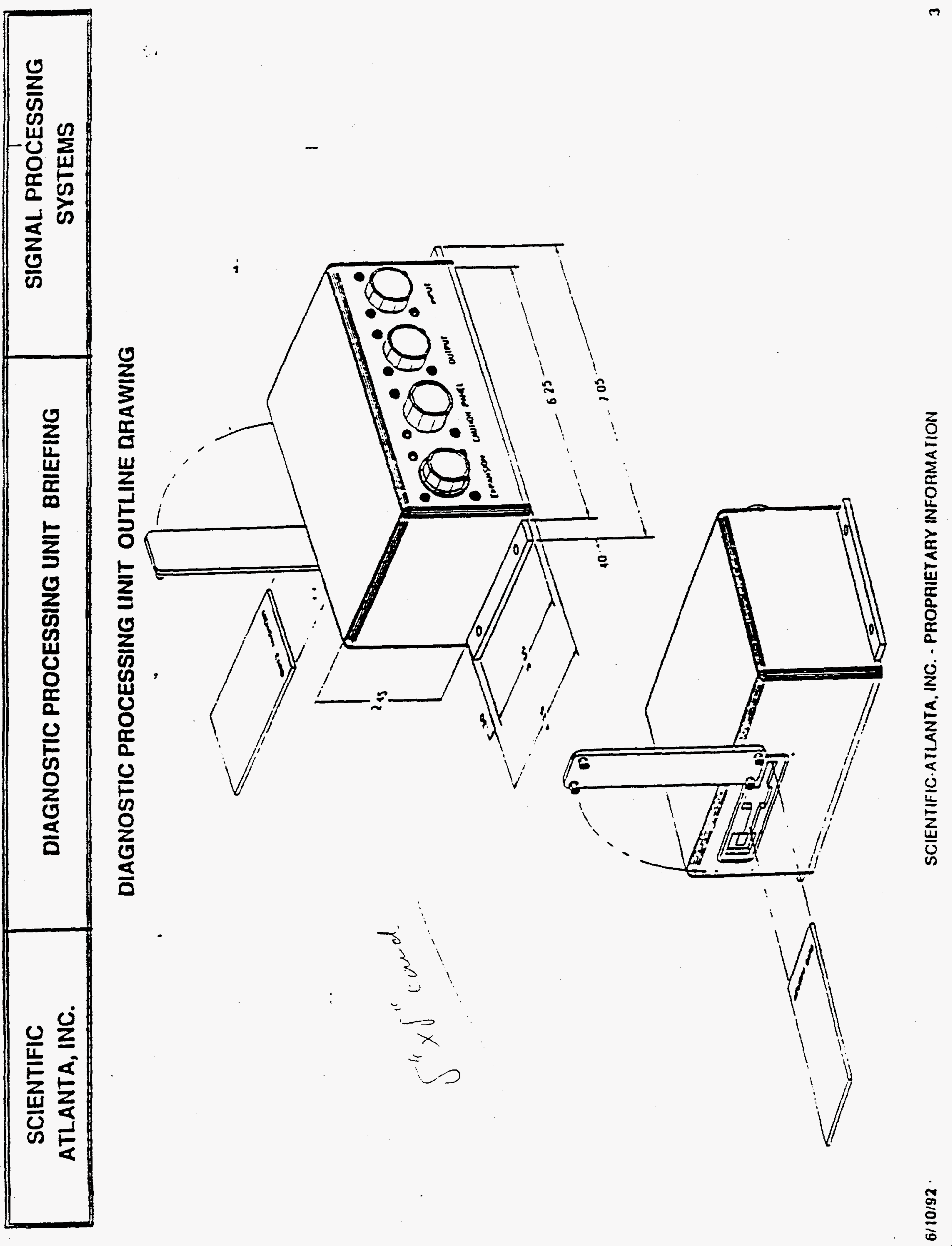



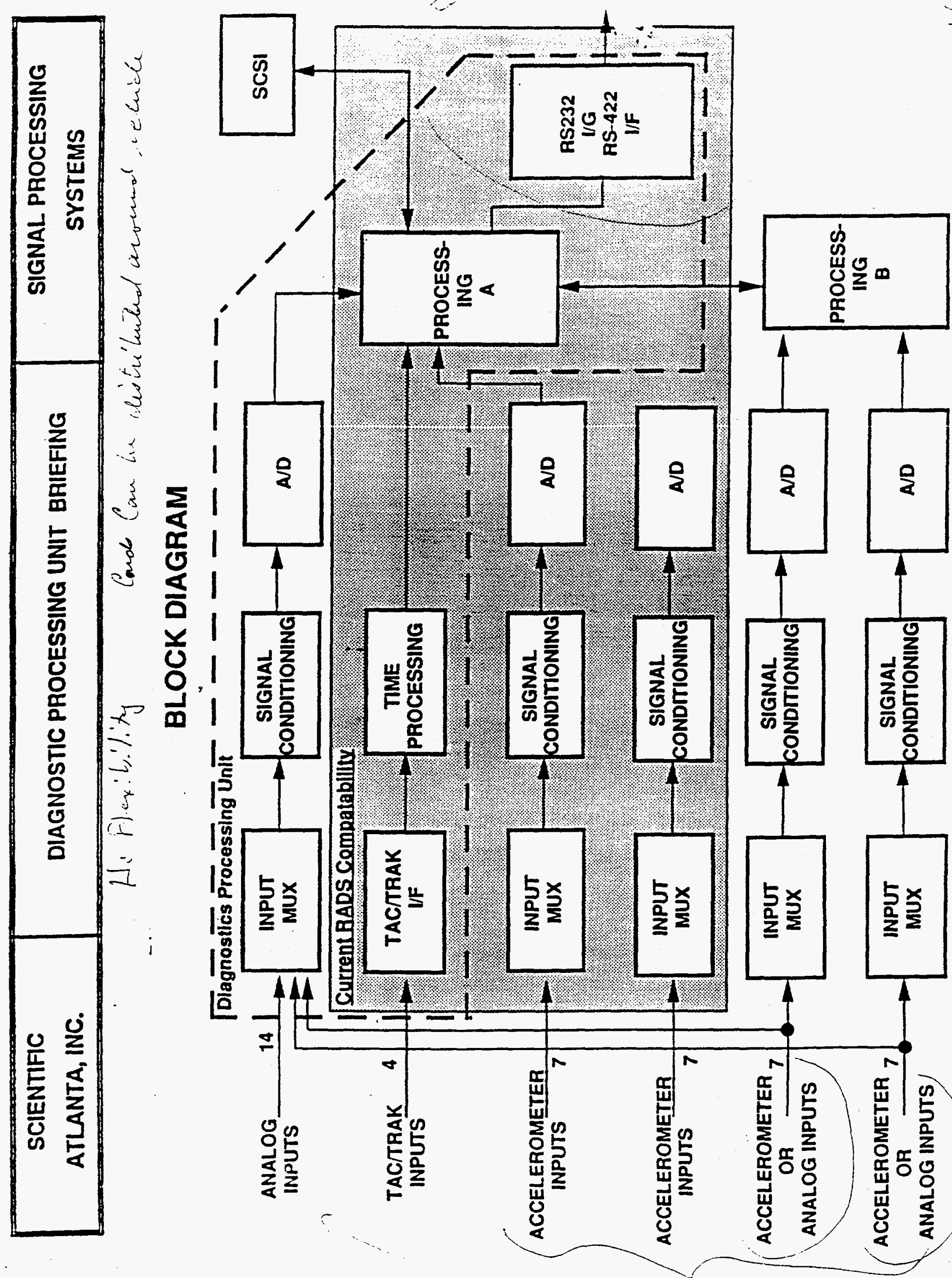

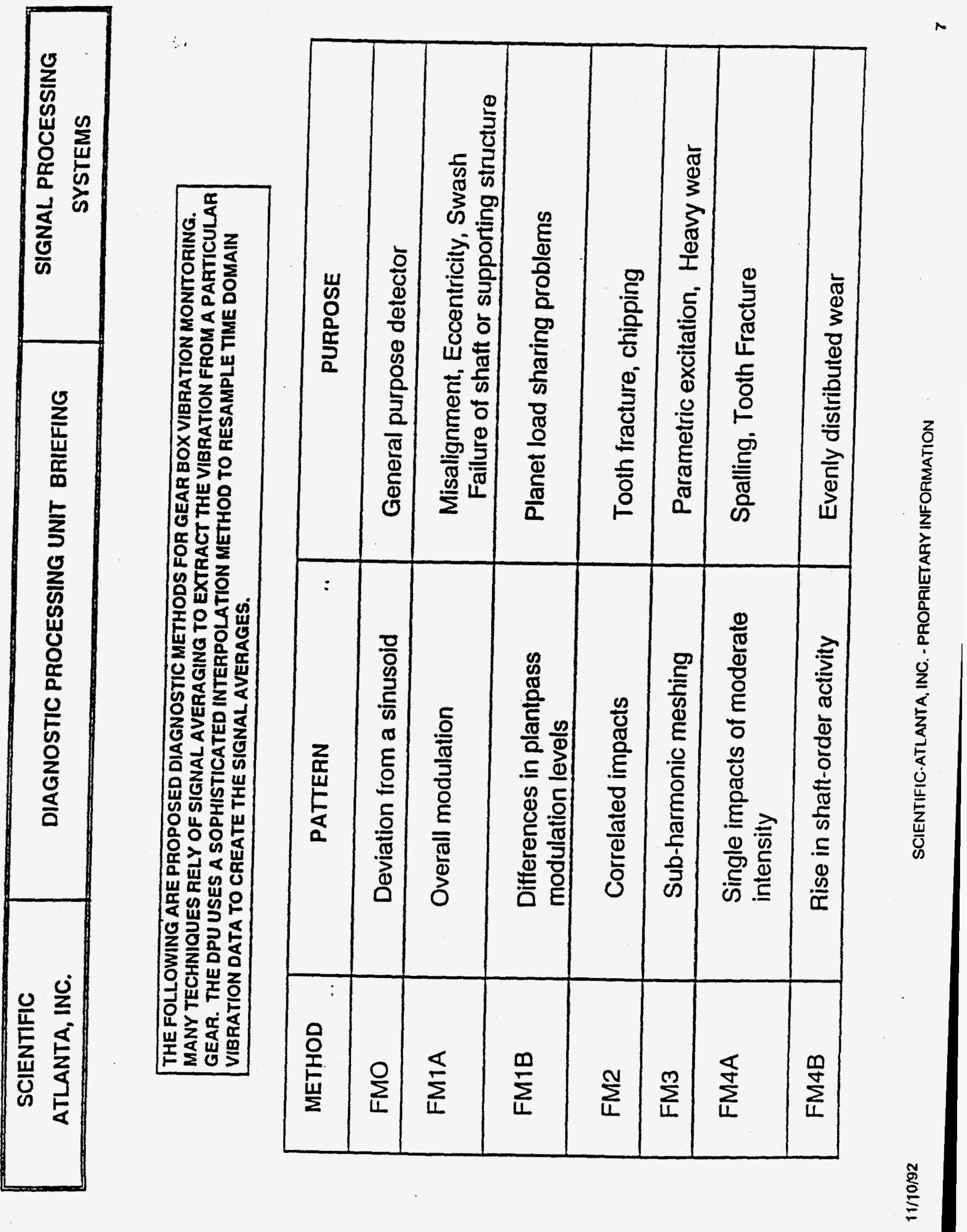

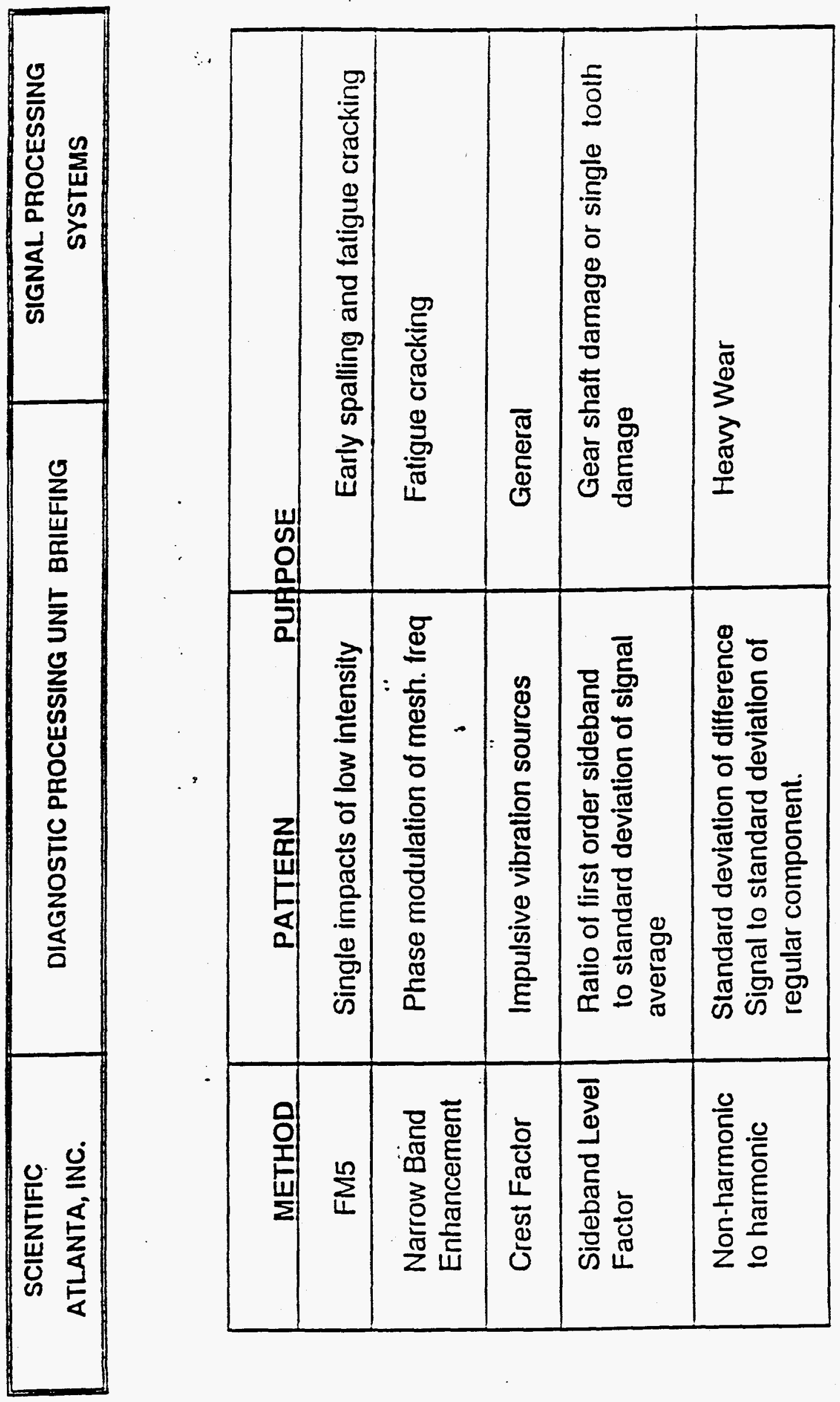


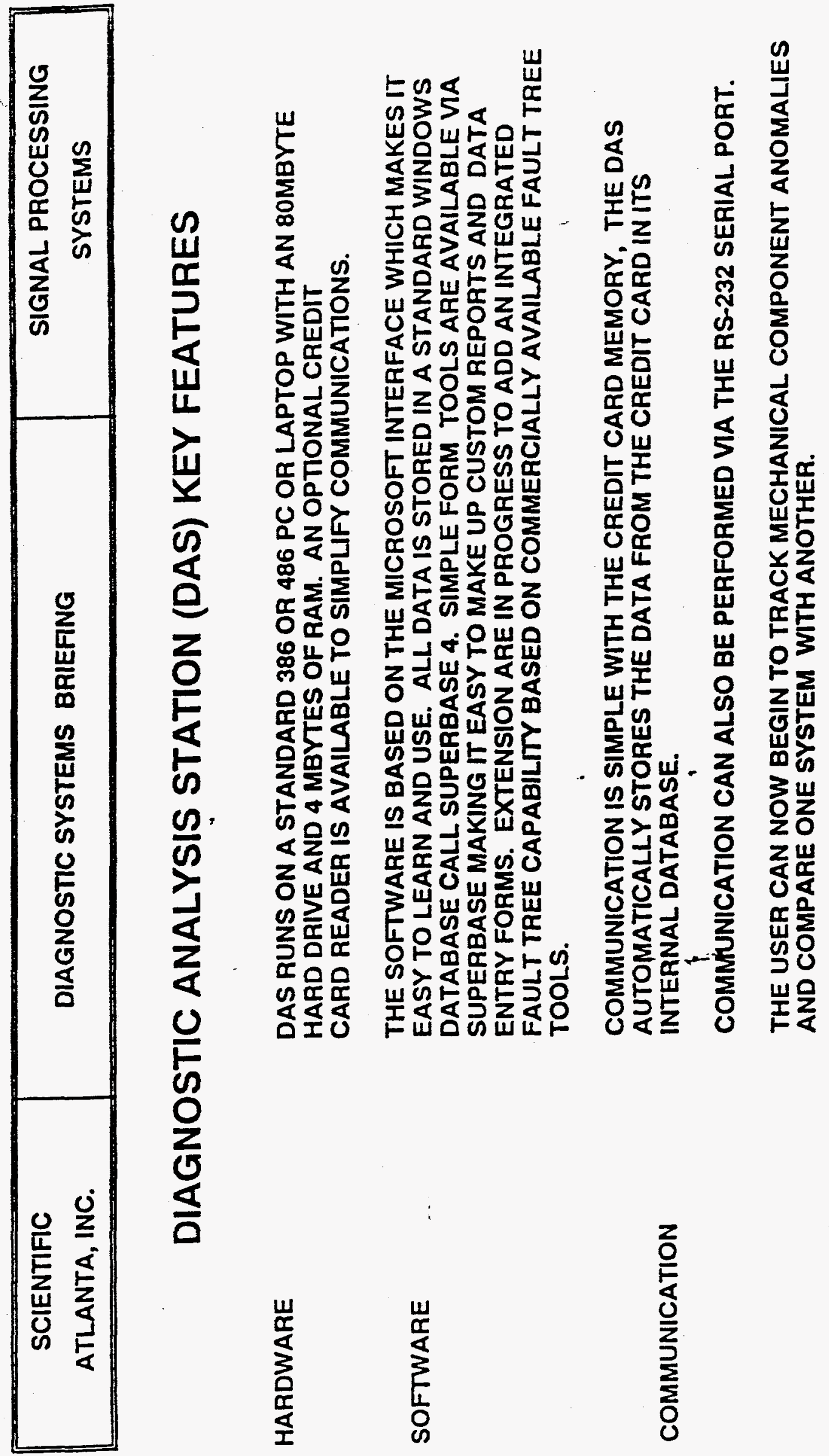

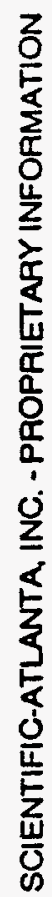




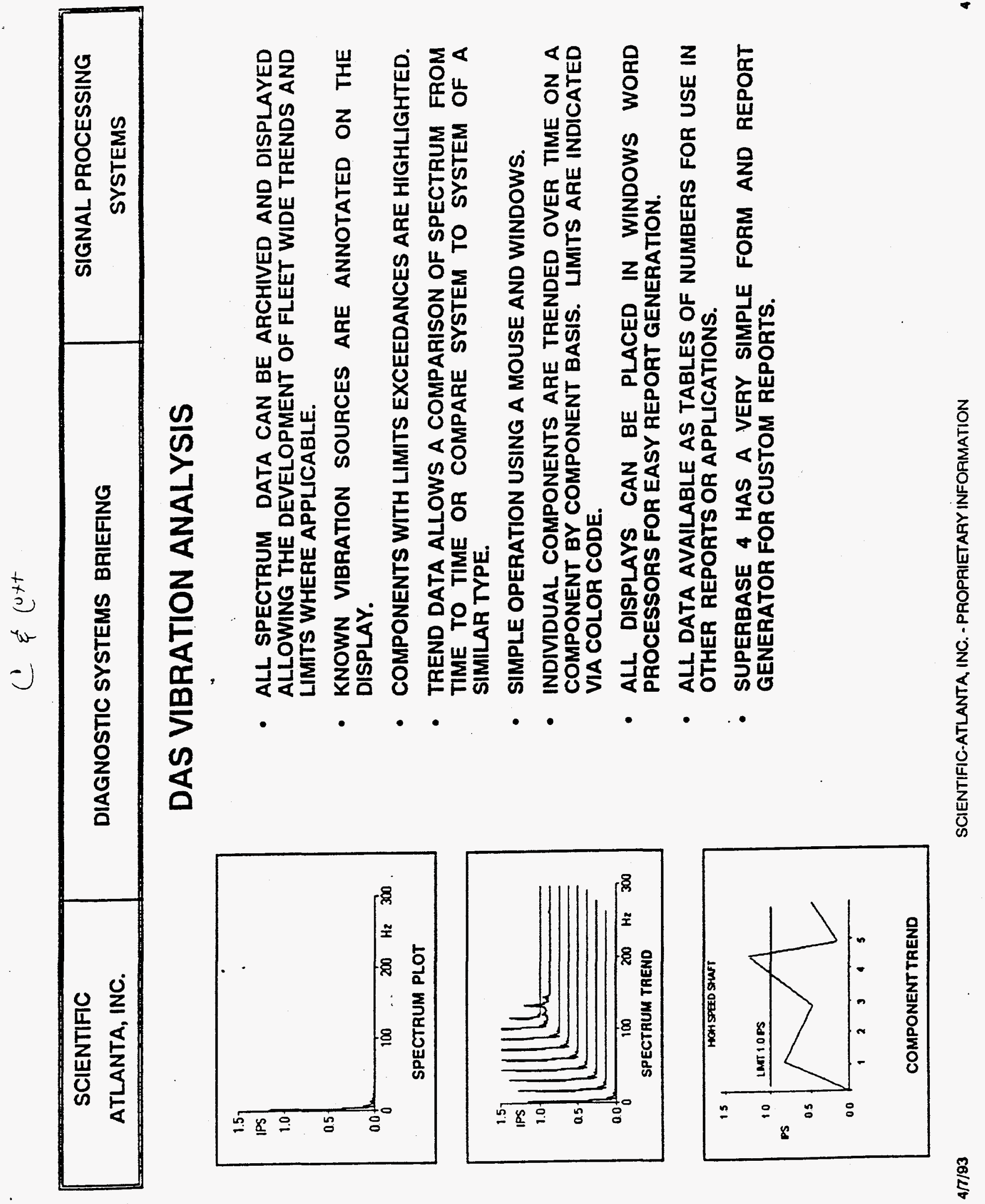




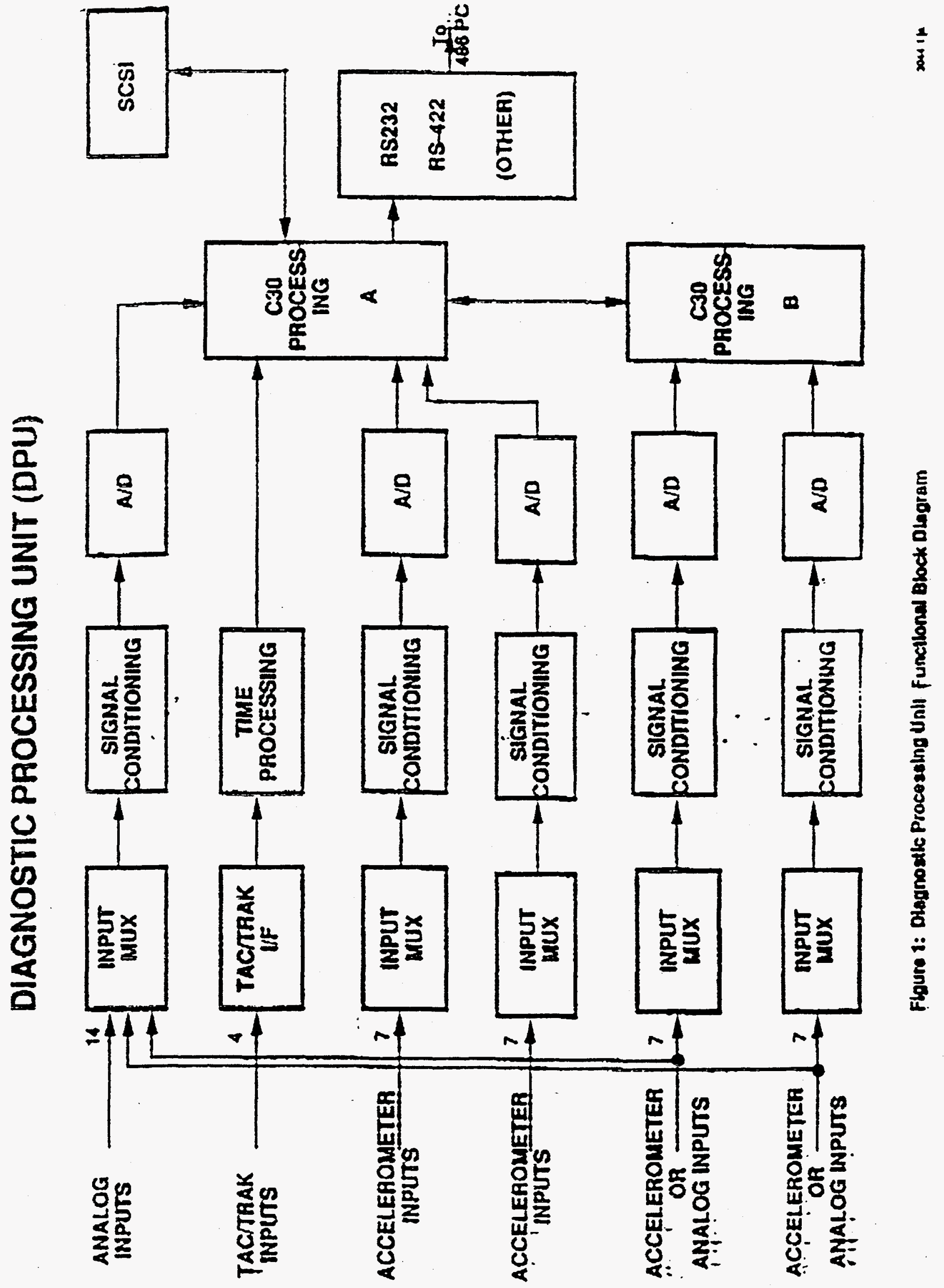




\section{proxirn \\ Date: July 20.1993}

Name: Don Brady

Fax $\$ 619-679.6200$

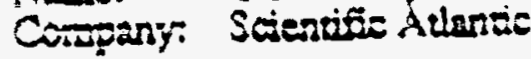

From: Mar Aver

Dear Don:

Tani you tor your interest in the Proxlinkix family of wireless asyachronous is -232 Truci. Fi:closed please find the intormation you reguested.

m-oxLuk is designed for users who need to extend asynch-onous connectivity 10 lxaduons

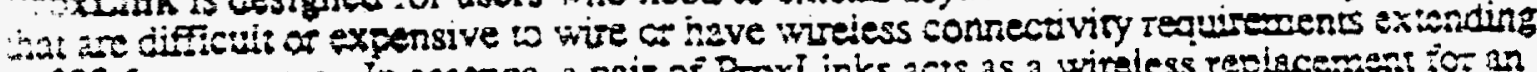
$\because 800$ ftet or more. In essence, a pair or Proxlinks acts as a wireless repiacersent tor an

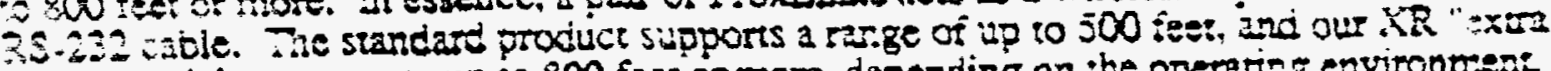
ange" nociel can operate up to 800 feet or toore, dependirg on the operatis senvirontent

From the factory floor wo office setrings to outdoor environochts, no RF communication is more reliable than Proxilink's spresd spectrun. Installation is easy and no FCC jite license is required

ProxLink is designed for applieadions such as:

- Pacrory floor data collection and NC downloading

- Connectiog dumb rerminais to a host

- Point-of-sale applications

- Building to building line-of-sight communications

- Process monitoring

- Any differit or extenced distance RS-232 connection

Enclosed please find the information you reques:ed. If you need further information of would like the name of the Proxim Represeniative nearest you. please caif us at (415) $960-1630$.

Thank you for your interest in Proxine's ProxLink.
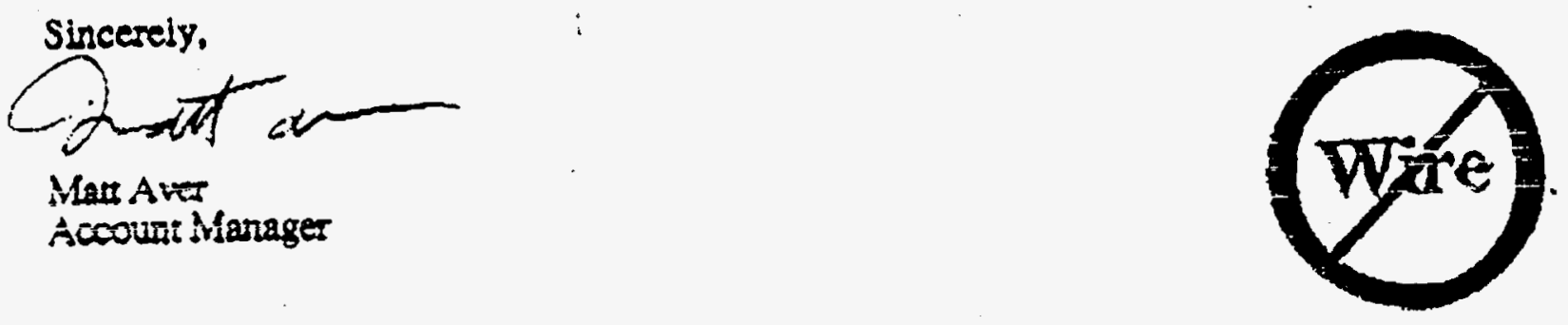

\footnotetext{
Thits. ince

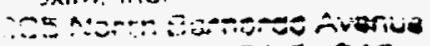

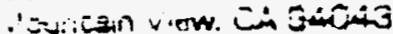

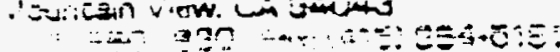




\section{FroxLink" Radio Moduie \\ mireless R.S.232 Connectuty}

\section{Overview}

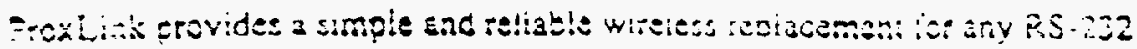

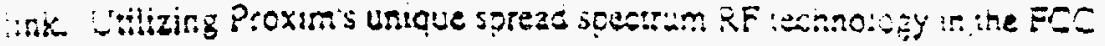

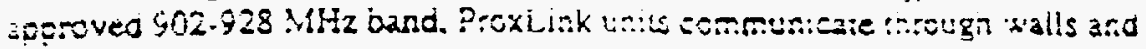
other oostructons.

Te standarc ProxLink oflers exceller: iniemediate :ange of abcut 500 fee:. -intie te ProxLiricXR provides exterded range capabilities ci $\$ 00$ feet c: mcre. depending on the speciffes of thi operational environment. (These isseances can be achieved. "out of the box" anywhere in the Linitec States.

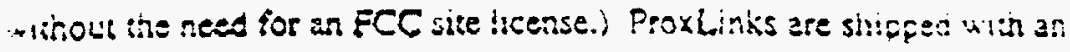
anterra, RS.332 cable, fower suppiy, and a full cre year warran:

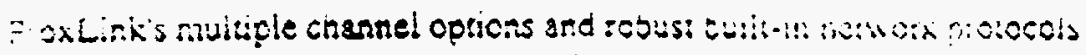

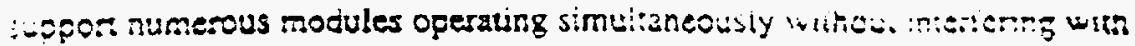

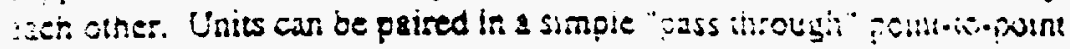
mode or opented in various other topologtes, witlizing the prostomntable hackelized mode eapability.

\section{Benefits}

- Plug-and-Play Instatlation - wireless RS-232 in minutes

- No FCC Size Licersing - Proxilink gives the user control of titeir own airwaves -without govemment licensing.

- Guerasteed Error-Free Communicazion - Spreed sp̣ectrun nactc and 100\% -roor desection ensure reliable connunicstion every t:me.

- Exzopnonal System Perjomance - RS-232 data rates ip to 19.2 Katud ifult dupiex) handle demanding serial appiteations.

- Flexioble Configuration Stored in EEPROM - A wide ange ci baud iates and fow centrol options can be selected and saved in ProxLink's non-volatile menory.

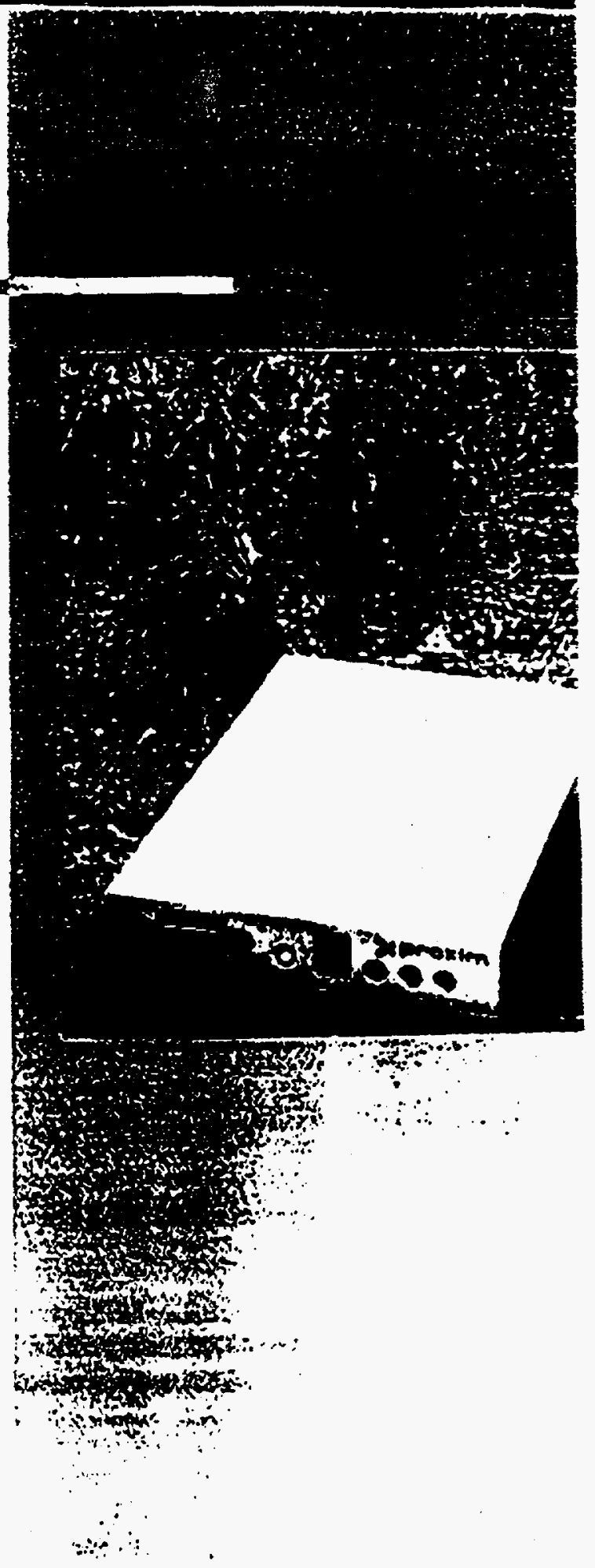

\section{Applications}

- Data Collection

- Mesasuring Systemes

- Process Monitoring

- Dexkioph aceop Computers

- Rersore Printera

- Envirenmental Monitoring

- Szcurity Systeons

\section{Devices}

- Setal Terminais

- Cara Readers

- Pesonal Computeis

- Scanners

- Priniess

- Programmatle Lagic Controilers

- Handheld Dala Recorcers 


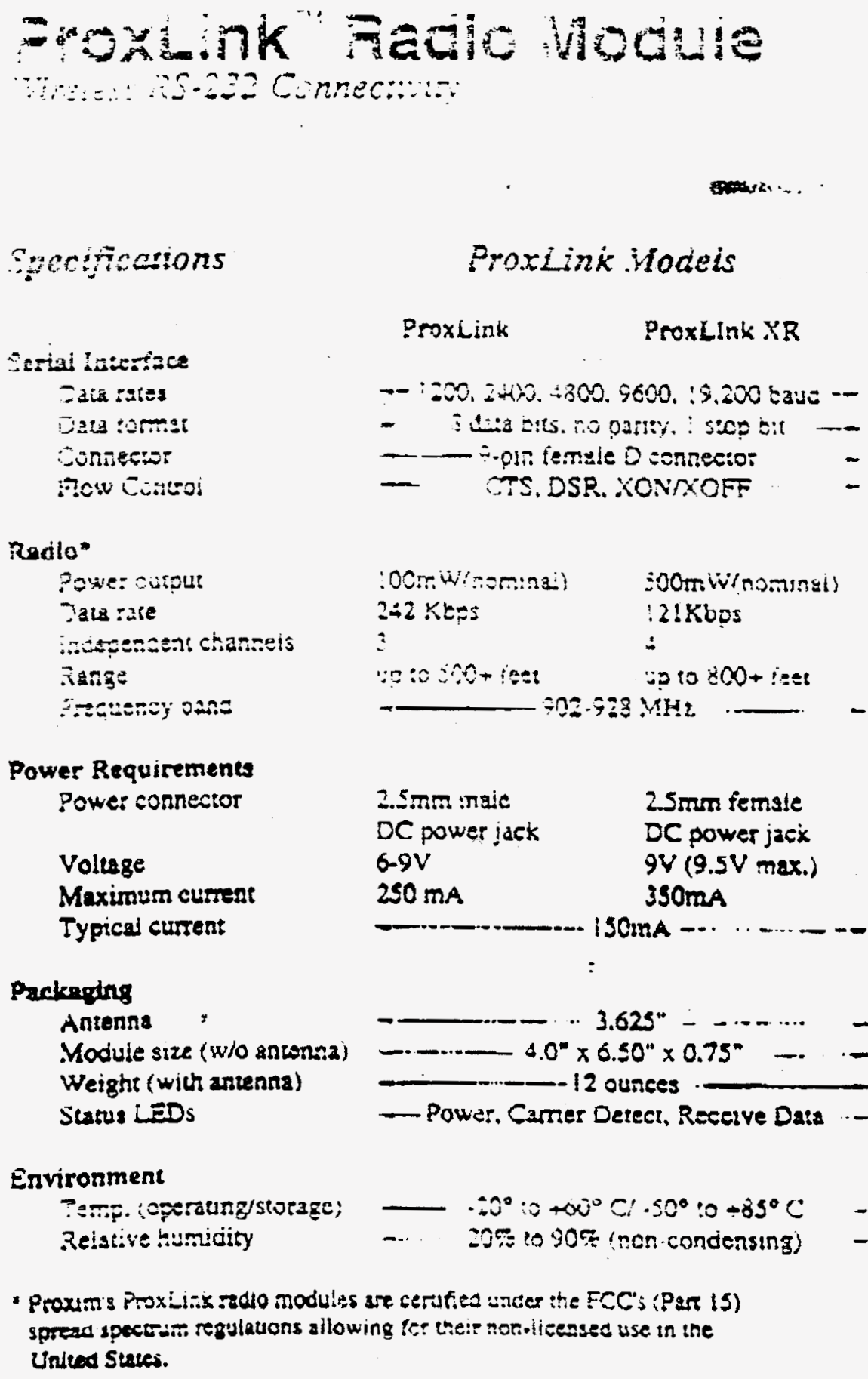

$2.5 \mathrm{~mm}: \mathrm{ngic}$ DC power jack 6-9V $250 \mathrm{ma}$

Maximum clirest

Typical current

\section{Packejing \\ Antenna \\ Module size (w/o antonsta) \\ Weight (with antenna) \\ Statu: LEDS}

\section{$2.5 m \pi$ femsle}

DC power jaex

9V $(9.5 \mathrm{~V}$ max.)

$390 \mathrm{ma}$

\section{Environment}

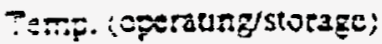

Relstive humidity

- Proxims Frox_isx zedo modules are cerutied uncer the FCC; (Par is) spread spect:-r. regulatuons silowing ie? the:r nor.ticessed use in the Unied States.

\section{Yoroxim}

Proxim. Inc.

zo5 Norh Bemardo Ave

Mouriers View, CA 94043

Phone (di5) $960-1630$ Fax (415) 964-5:81

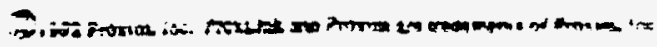

Pxdx:282 


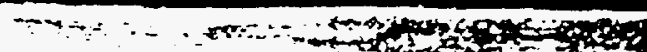

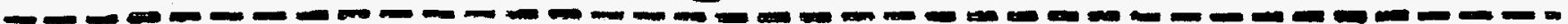

\author{
Questions and Answers \\ about ProxLink/XR Radio \\ Modules from Proxim. Inc.
}

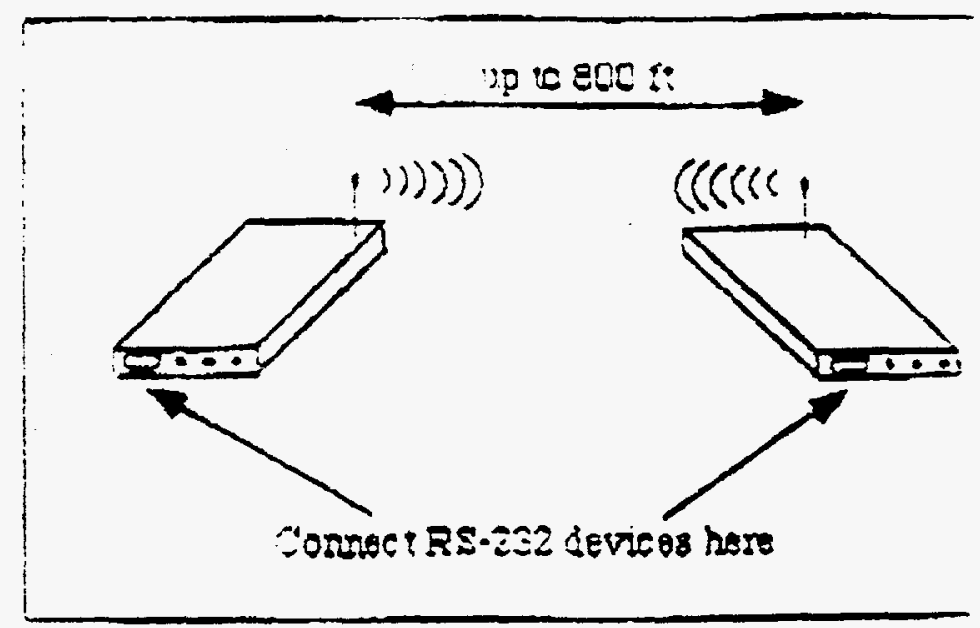

\section{What is Prost.ink:}

ProxLink is a spread spectrum radio module which permits almost any RS.232 connection to be replaced with a transparent wireless connection. You simply plug your RS-232 devices into a pair 0 : ProxLiniss and obtain a wireless RS-232 link with a range of up 10800 feet with the XR version.

\section{How den is work:}

FroxLink uses spread spectrum radio signals in the 902-928 MHz range to pass the RS-232 data stre: through the air. Spread spectrum cechnology offers excellent interference iejection and reguires no user FCC iicense. The signal will penetrate mose walls, glass. wood, plaster. and other commonly io obstruetions. Unlike other wireless systems, ProxLink does not require line of sight positioning.

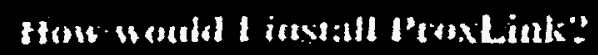

You will need a pair of Poxiniks in order to wirelessly conneet two RS. II I devices tcgether -- ore Froxink at each end. The ProxLink units draw power tront a wail outle? using the AC ddapter inch with esch Prox Link module. Once the units are plugged in. Your RS -232 devices can be connec:ed: the serial por on each unit. Instailation typically takes less than an hour.

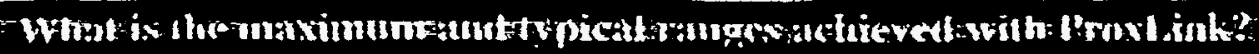

Typical ranges for Proxlink are summarized in the able beiow:

\section{Environumens}

Indoors, unobstructed environment such as a warehouse Indoors. through typical indoor obstructions

Ouldoors, with line of signt
Bange

-800 fee:

$-200-500$ feet*

-1 mile or more

- Depends on environment

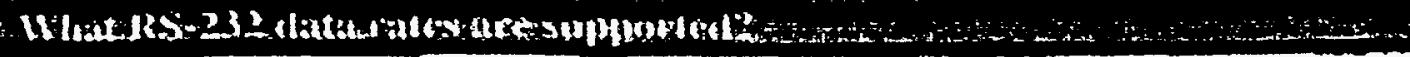

Proxinik supports 1200. - \$00. 4500.9600 , and 19.20 bave data ra:es.

Data tormat: 8 data bits. istop bit, no parity 


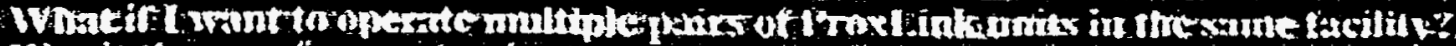

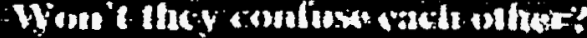

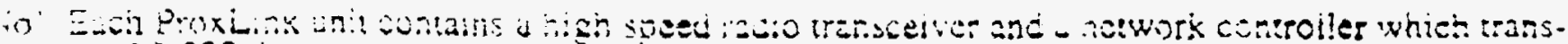

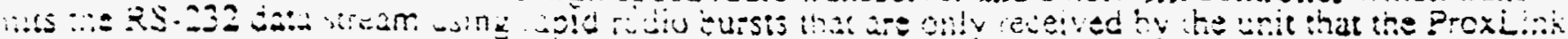

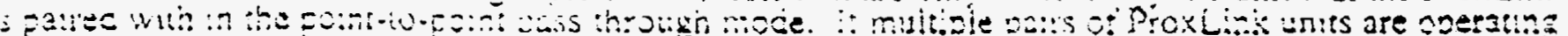

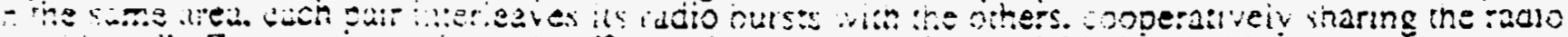

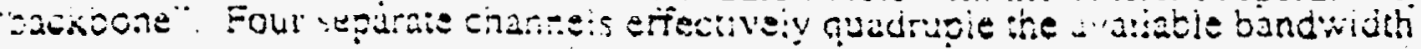

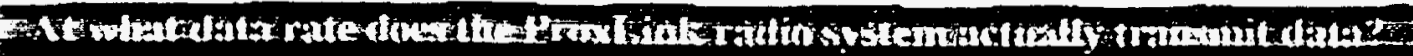
$\therefore=8$

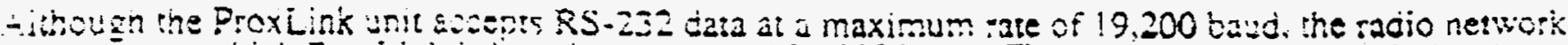

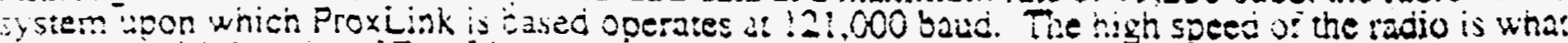
ferm:ts nuttiple pars ce ProxL:-x untes to "share the dirwaves" without slowing down or contusing saen othet.

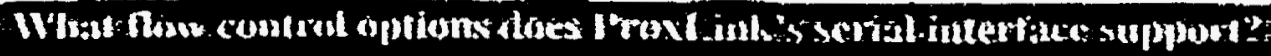

Proxi.rk supports "in burd" tow control (CTL-S. CDL.Q which is also known as XON/XOFE).

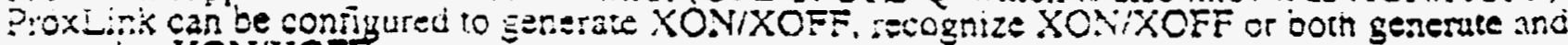
:ecognize XON/XOFF.

Froximis san who be connigured to generate the CTS signal and respont to an RTS signal.

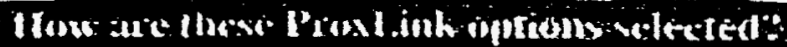

Each. Proxlink unit contains firmware which allows the user to set the parameters which control the behavior of the ProxLink unit. To activate the configuration frrmware. the user connects an ASCII iermunal :o the ProxLink's serial connector and presses the smail contiguration burton on the Pyoxíijx device. When this is done, the ProxLink unit displays a menu on the terminal (nose that a PC running terminal emulation software may also serve as a terminal).

Once the Proxlink is in terminal mode, it is very easy to set the parameters which control the RS-232 configuration (flow control. baud rate. exc). As each parameter is seiected and cinanged, the settings are recorced in the ProxLink's nonvolarile EEPROM storage. Once a contiguration has been selectec. the Proxlirk will remember the settings, even while it is turned off.

After parameter settings have been selected. the user can start the Proxlink unit from the menu by selecrng "Launch Operating Mode". The unit will start up ready to accept data in the new configuraion.

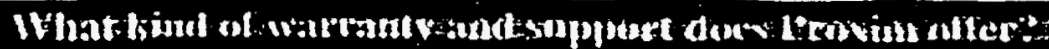

Each Prox Link unit comes with a full one (1) year waranty.

iechnical support is available from Proxim at (415) 960-1630.

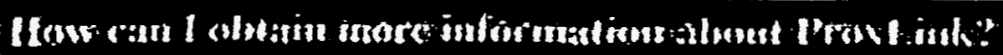

For intormation about ProxLink and the name of your local Proxim representative, contact Proxim at (415) 960 - 1630 .

We may also be reached by FAX af (415) $964-5181$.

¿1992 ty Froxim. Inc. ProxLinx uns P:oxim afe :rudercarxs of Proxim. Inc.

\section{proxim}

zes Nor-: Eernardo Áventa

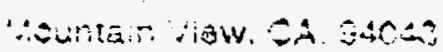

COnE $1=: 51950.1530$

Fax $4: 5 ; 384.5:$ 


\section{Scientific \\ Atlanta}

\section{TerraStar-C Satellite Terminal}

Network Systems Group

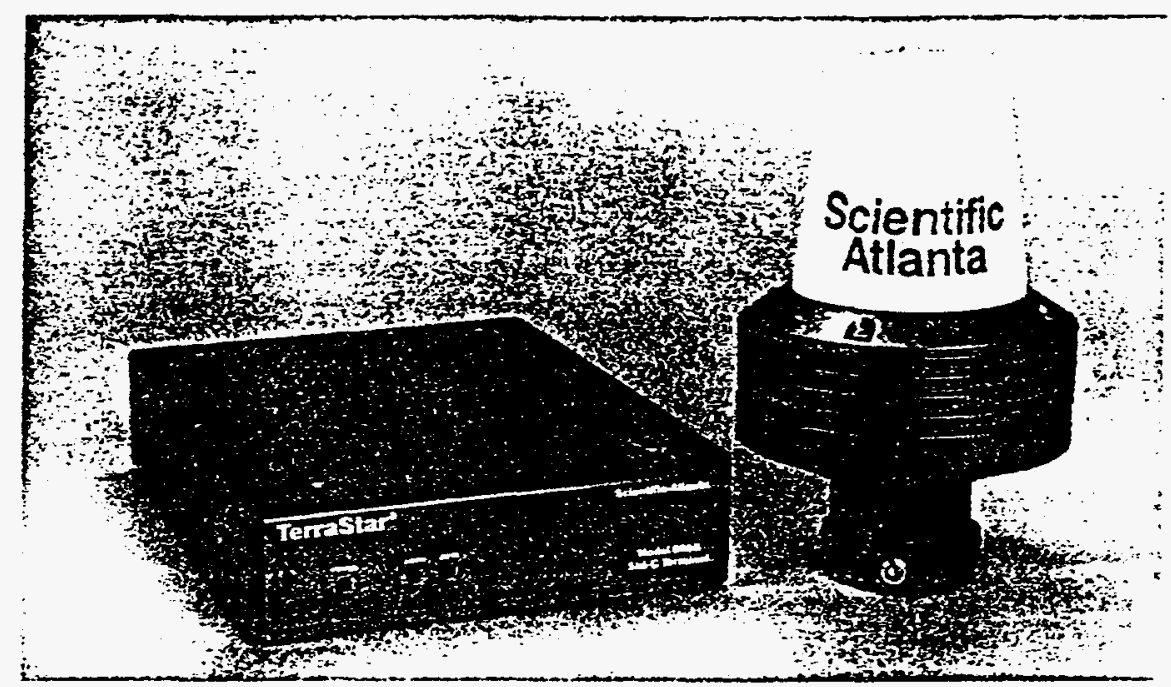

The Model 9805 TerraStar-C Satellite Terminal offers global data or telex communication through the Inmarsat Standard 'C' System. The system is easy to operate and connects with either an ASCII terminal or personal computer. With the optional GPS Receiver, precise position determination is available through the same antenna.

\section{Features}

- Smallest, lightest weight Inmarsat-C terminal available

- 2-way message and data communication to any destination

- Automatic data and position reporting

- Standard interface to NMEA 0183 navigators

- GPS interface 50-ohm SMA connector

\section{Description}

The Model 9805 offers Land Mobile users fast and reliable connections to any domestic or international telex or data network. Fast and reliable 2-way transfer of any type of written message or data is supported along with data reporting transmission and automatic polling of terminal position.

Operation and control of the Model 9805 is performed via a standard RS-232 communications port. The unit can be operated from either a standard ASCll terminal or an MS-DOS based desk-top, portable, or lap-top personal computer.

INMARSAT

Scientific-Atlanta, Inc. 404-903-6001 


\section{System Specifications}

Meets or exceeds all current and proposed Inmarsat specifications for inmarsat-C system.

Transmit Frequency 1626.5 to $1646.5 \mathrm{MHz}$

Receive Frequency 1530.0 to $1545.0 \mathrm{MHz}$

Channel Spacing

$5 \mathrm{kHz}$

\section{Indoor Unit Specifications}

Modulation

1200 symbols/second BPSK

Ambiguity Resolution

Unique word

\section{Coding}

Rate $1 / 2, k=7$ convolutional code with interleaved code symbols

Data Rate

$600 \mathrm{~b} / \mathrm{s}$

Receive Frame Length

8.6 seconds

Transmit Signalling Access Mode

Slotted ALOHA

Transmit Message Channel

TDMA \& FDMA, interleaved code symbol

Terminal Interface

CCITT rec. V. 24/28, 9-pin female D-connector.

$110-9600$ baud, ITA-5 code, max. 100 meter cable

Printer Interface

Standard parallel Centronics, 25-pin female D-connector. max. 4 meter cable

Navigator \& Alarm Interface

CCITT Rec. V.10 Special with NMEA 0183 interface and multidrop addressing, BNC-female connector, max.

100 meter cable

Antenna interface

Standard 50 ohm female $\mathrm{N}$-connector, max.

100-meter cable

Memory

256 kbyte RAM

\author{
System Programming \\ EEPROM programming of installation parameters from \\ operator's terminal \\ DC Power Source \\ Ambient Temperature \\ 10.5 to $32 \mathrm{~V} \mathrm{dc}, 9.5 / 80 \mathrm{~W}$ \\ $.25^{\circ} \mathrm{C}$ to $55^{\circ} \mathrm{C}$ operating. \\ $-40^{\circ} \mathrm{C}$ to $80^{\circ} \mathrm{C}$ storage \\ Relative Humidity \\ $95 \%$ non-condensing \\ Vibration \\ Operational \\ Fandom 5 to $20 \mathrm{~Hz}, 0.02 \mathrm{~g}^{2} / \mathrm{Hz}$. \\ 20 to $150 \mathrm{~Hz} \cdot 3 \mathrm{~dB} /$ Oct. (1.0 g rms) \\ Survival \\ Random 5 to $20 \mathrm{~Hz}, 0.05 \mathrm{~g}^{2} / \mathrm{Hz}$, \\ $2010150 \mathrm{~Hz}-3 \mathrm{~dB} /$ Oct. $(1.7 \mathrm{~g} \mathrm{rms}$ ) \\ Shock \\ Half sine, $20 \mathrm{~g} / 11 \mathrm{~ms}$ \\ Mounting \\ Free standing cabinet with mounting brackets or optional \\ 19 inch mounting kit \\ Dimensions \\ $2.4 \mathrm{in}(62 \mathrm{~mm}) \mathrm{H} \times 8.5$ in $(214 \mathrm{~mm}) \mathrm{W} \times 11$ in $(279 \mathrm{~mm}) \mathrm{D}$ \\ Weight \\ $7.04 \mathrm{lbs}(3.2 \mathrm{~kg})$
}

\section{Antenna Specifications}

Meets or exceeds all Inmarsat specifications

for antenna pattern and EIRP.

$\begin{array}{ll}\text { Weight } & 4.2 \mathrm{lbs}(2.0 \mathrm{~kg}) \\ \text { Height } & 6.9 \text { inches }(176 \mathrm{~mm}) \\ \text { Max. Diameter } & 5.9 \text { inches }(150 \mathrm{~mm}) \text {, Conical } \\ \text { Ambient Temperature } & -35^{\circ} \mathrm{C} \text { to } 55^{\circ} \mathrm{C} \text { operational, } \\ & -40^{\circ} \mathrm{C} \text { to } 70^{\circ} \mathrm{C} \text { storage } \\ \text { Spray } & \text { Solid droplets (AU) } \\ \text { Ice } & \text { Up to } 2.5 \mathrm{~cm}(\mathrm{AU}) \\ \text { Precipitation } & \text { Up to } 10 \mathrm{~cm} / \mathrm{h} \mathrm{(AU)} \\ \text { Wind } & \text { Up to } 100 \mathrm{knots}(\mathrm{AU}) \\ \text { Vibration } & 2 \text { to } 10 \mathrm{~Hz}, 1.0 \mathrm{~g} \text { peak } \\ \text { Mounting } & 1-1 / 2 \text { inches tube mounting }\end{array}$

Specifications and product availability are subject to change without notice.

\section{Scientific-Atlanta, Inc.}

Our customers are the winners.

\footnotetext{
United States: 4291 Communications Drive, Norcross, GA 30093, Tel: 404-903-6001. IT Telex: 4611804

Australia: Unit 2.2 Aquatic Drive, Frenchs Forest. N.S.W. 2086. Australia. Tel: (02)-452-3388. Telex: 177418 France: 4 Avenue Gabriel Peri. 78360 Montesson, France. Tel: 13-976-9191, Telex: 696385

Germany: Abber-Schweitzer-Strasse 66. 8000 Munich 83. Postfach 830935. Germany, Tel: 48-6780010. Telex: 5212264 Italy: Via Benedetto Croce, 19,00142, Rome. Italy. Tel: 6-5420244, Telex: 621441

United Kingdom: Home Park Estate, Kings Langtey, Herts WO4 8LZ, England, Tel: 092-326-6133, Telex: 912044

42D151Z C Copyright 1992 Scientific-Atlanta, Inc. All rights reserved. Printed in USA. $1092 \mathrm{M} 0255$
} 


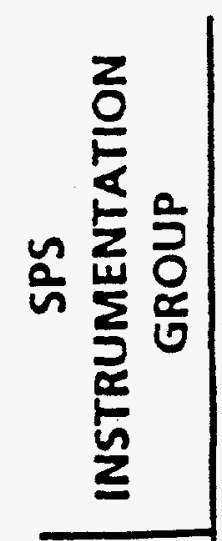

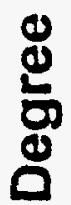

$\frac{1}{0} \stackrel{0}{0}$

$\frac{9}{8}$
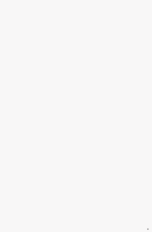

$\underline{2}$

ช $\frac{6}{8}$

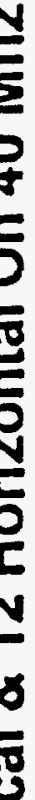

$\rightarrow 5$

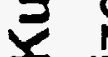

2

는

$=$

II)

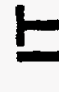

$\frac{1}{0}+1$

Z E

$F$

$\Sigma$

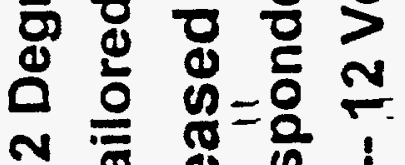

(1) $10 \frac{2}{6}$

$<0_{0}^{0} \frac{1}{0}$

- $00 \%$

$\infty$ o $\infty$

$<0 \frac{8}{8}$

\& $匚$ \&

苋

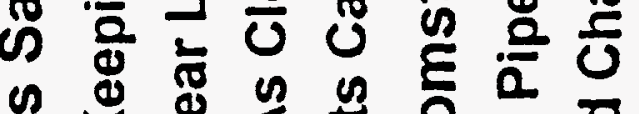

乌

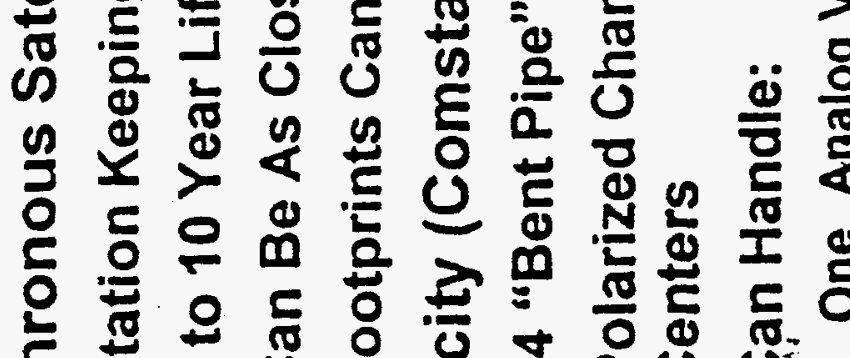

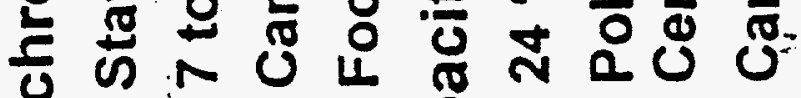

离

8

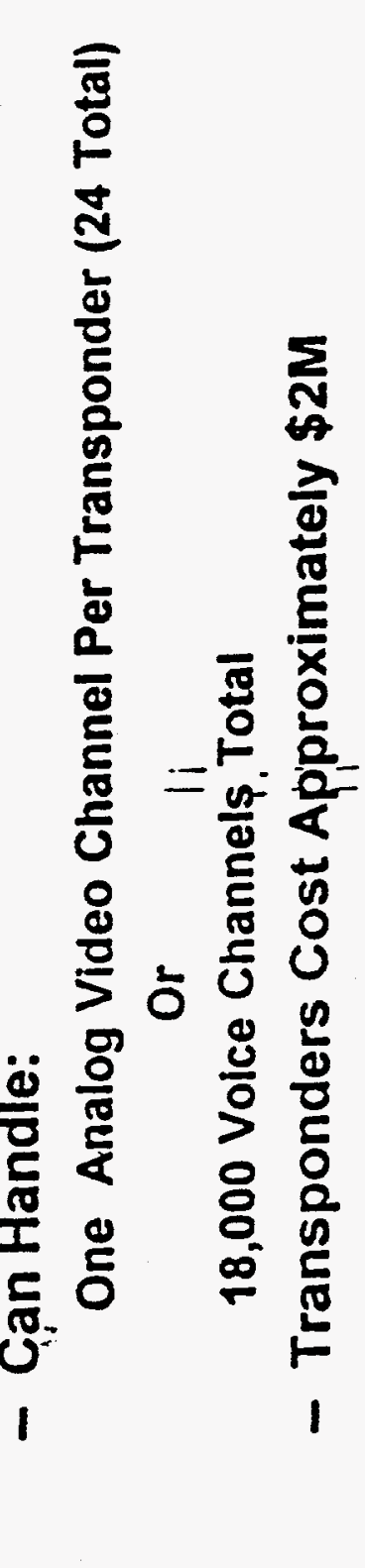

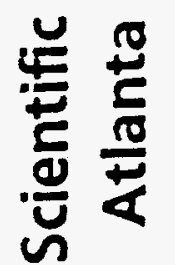




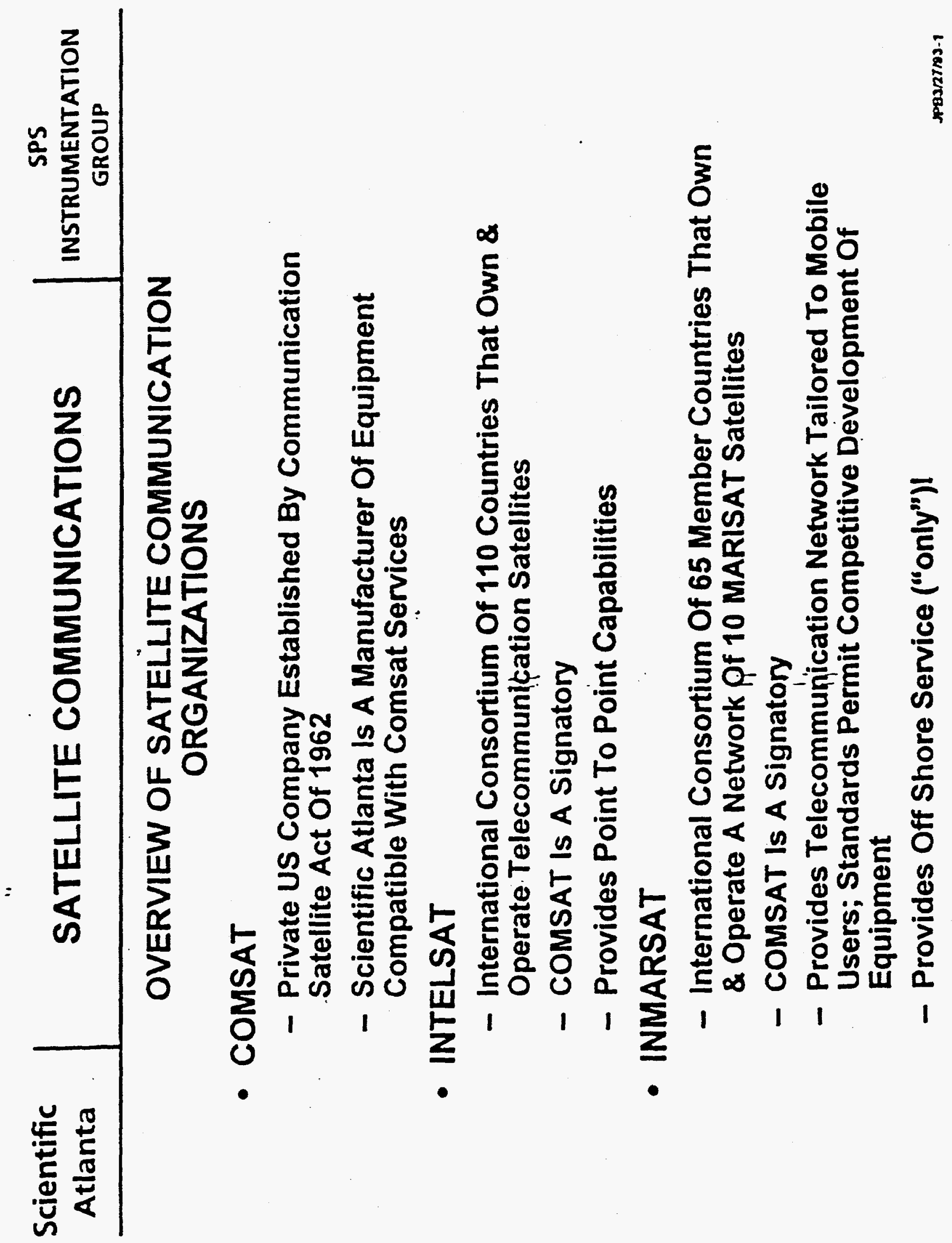




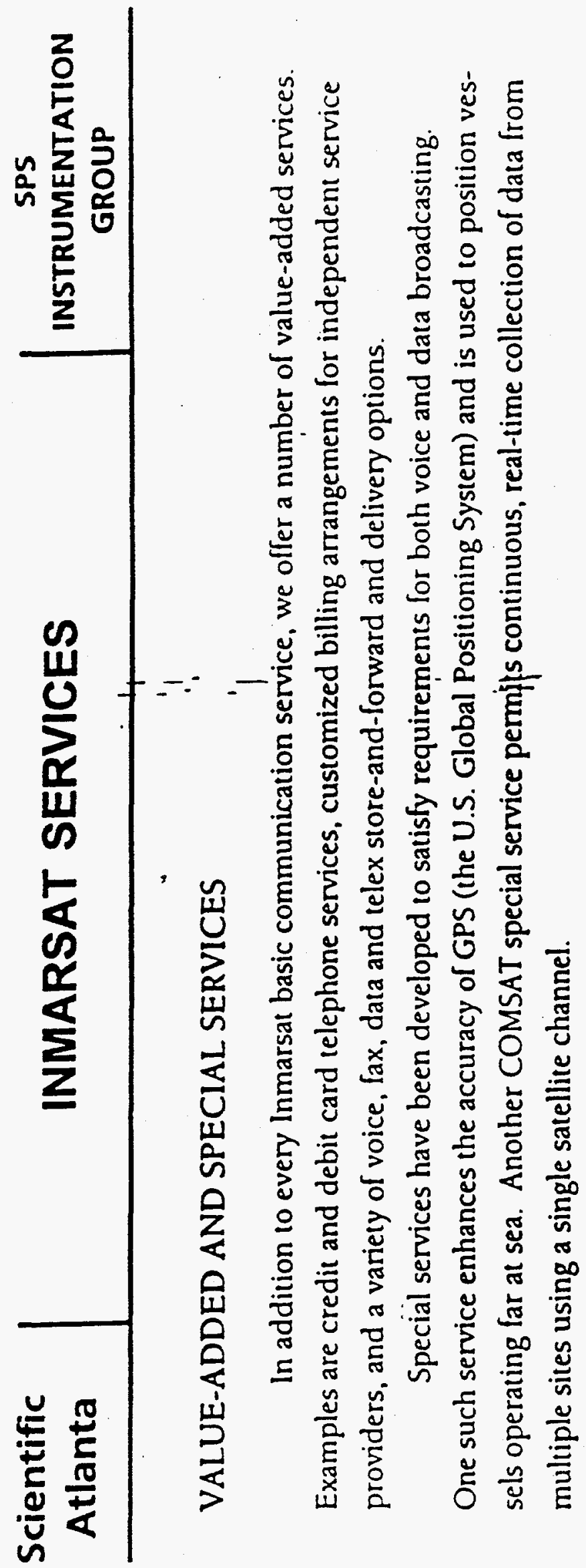

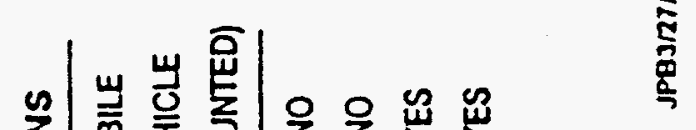




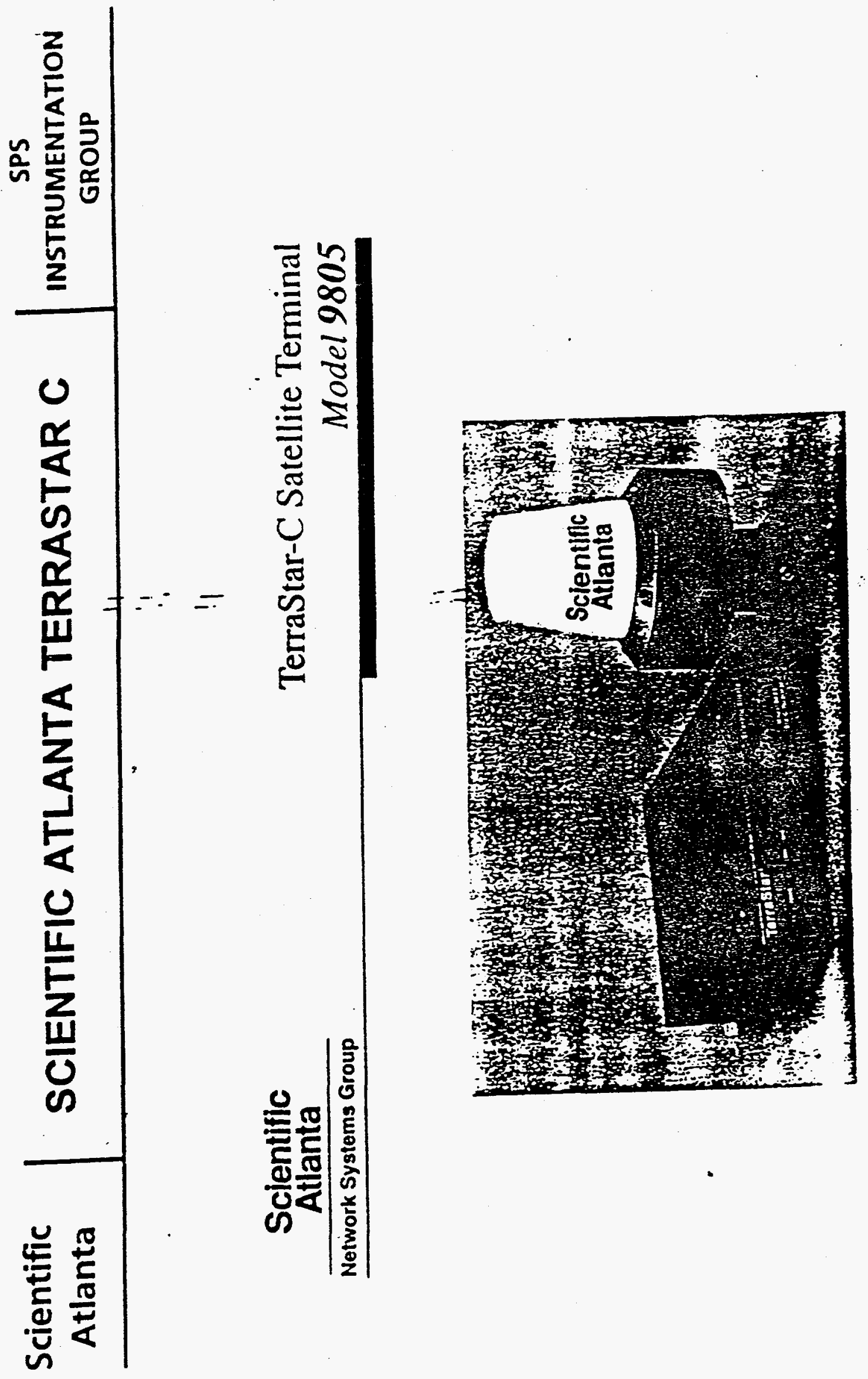




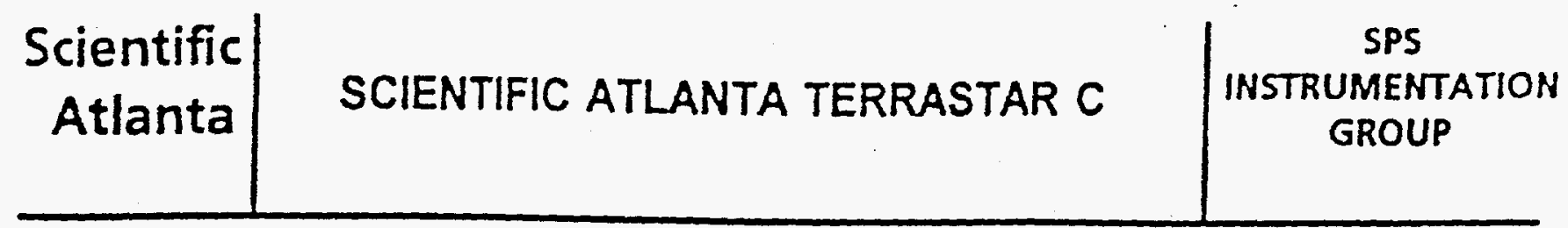

Model 9805 TerraStar-C Satellite Terminal

mows

\section{System Specifications}

Meets or exceeds all current and proposed Inmarsat

specifications for inmarsat-C system.

7

Transmit Frequency

1626.5 to $1646.5 \mathrm{MHz}$

Recoive Frequency

1530.0 to $1545.0 \mathrm{MHz}$

Channel Spacing

$5 \mathrm{kHz}$

Indoor $\overline{\bar{U}} \overline{\bar{t}} \overline{\text { Speciffeations }} \quad: \quad==$

Modulation

1200 symbols'second BPSK

Ambiguity Resolution

Unique mord

Coding

Rate 1/2, k=7 convolutional code with interleaved code symbols

Data Rate

$.600 \mathrm{brs}$

Receive Frame Length

8.6 seconds

Transmit Signalling Acoess Mode

Slotted ALOHA

Transmit Message Channel

TDMA \& FDMA, interleaved code symbol

Terminal Intertace

CCITT rec. V. 24728, 9-pin temale D-connector.

110-9600 baud, ITA-5 code, max. 100 meter cable

Printer Intertace

Standard parallel Centronics, 25-pin female D-connector, max. 4 meter cable

Navigator \& Alarm tntertace

CCIT Rec. V.10 Spocial with NMEA 0183 interface and muttidrop addressing, BNC-female connector, max.

100 meter cable

Antenna Intertace

Standard 50 ohm female N-connoctor, max.

100-meter cable

Memory

256 kbye RAM
System Programming

EEPROM programming of installation parameters from operator's terminal

DC Power Source

Ambient Temperature

10.5 to $32 \mathrm{~V} \mathrm{dc}, 9.5 / \mathrm{BOW}$

$-25^{\circ} \mathrm{C}$ to $55^{\circ} \mathrm{C}$ operating.

$-40^{\circ} \mathrm{C}$ to $80^{\circ} \mathrm{C}$ storage

Relative Humidity

95\% non-condensing

Vibration

Operational

Fandom 5 to $20 \mathrm{~Hz}, 0.02 \mathrm{~g}^{2} / \mathrm{Hz}$. $2010150 \mathrm{~Hz} \cdot 3 \mathrm{~dB} / \mathrm{OCt}$. (1.0 g ms).

Survival Random $51020 \mathrm{~Hz}, 0.05 \mathrm{~g} / \mathrm{Hz}$. 20 to $150 \mathrm{~Hz}-3 \mathrm{~dB} / \mathrm{OCt}$. (1.7 g ms)

Shock Hall sine, 20g/11 ms

Mounting

Free standing cabinet with mounting brackets or optional 19 inch mounting kit

Dimensions

2.4 in $(62 \mathrm{~mm}) \mathrm{H} \times 8.5$ in $(214 \mathrm{~mm}) \mathrm{W} \times 11$ in $(279 \mathrm{~mm}) \mathrm{D}$ Weight

$7.04 \mathrm{bos}(3.2 \mathrm{~kg})$

\section{Antenna Specificatlons}

Meets or excoeds all Inmarsat specifications for amenna partem and EIRP.

Weight

$4.2 \mathrm{bs}(2.0 \mathrm{~kg})$

Height

6.9 inches $(176 \mathrm{~mm})$

Max. Diameter

5.9 inches $(150 \mathrm{~mm})$. Conical

Ambient Temperature $-35^{\circ} \mathrm{C}$ to $55^{\circ} \mathrm{C}$ operational. $-40^{\circ} \mathrm{C}$ to $70^{\circ} \mathrm{C}$ storage

Spray

Solid droplets (AU)

10

Precipitation Up to $2.5 \mathrm{~cm}$ (AU)

Wind

Vibration

Mounting Up $1010 \mathrm{cmm}$ (AU) Up 10100 knots (AU) 2 to $10 \mathrm{~Hz}, 1.0 \mathrm{~g}$ peak 1-1/2 inches tube mounting

Specifications and product availability are subject to change without notice. 


\begin{tabular}{r|c|c}
$\begin{array}{r}\text { Scientific } \\
\text { Atlanta }\end{array}$ & SCIENTIFIC ATLANTA MAPSTAR & $\begin{array}{c}\text { SPS } \\
\text { INSTRUMENTATION } \\
\text { GROUP }\end{array}$ \\
\hline
\end{tabular}
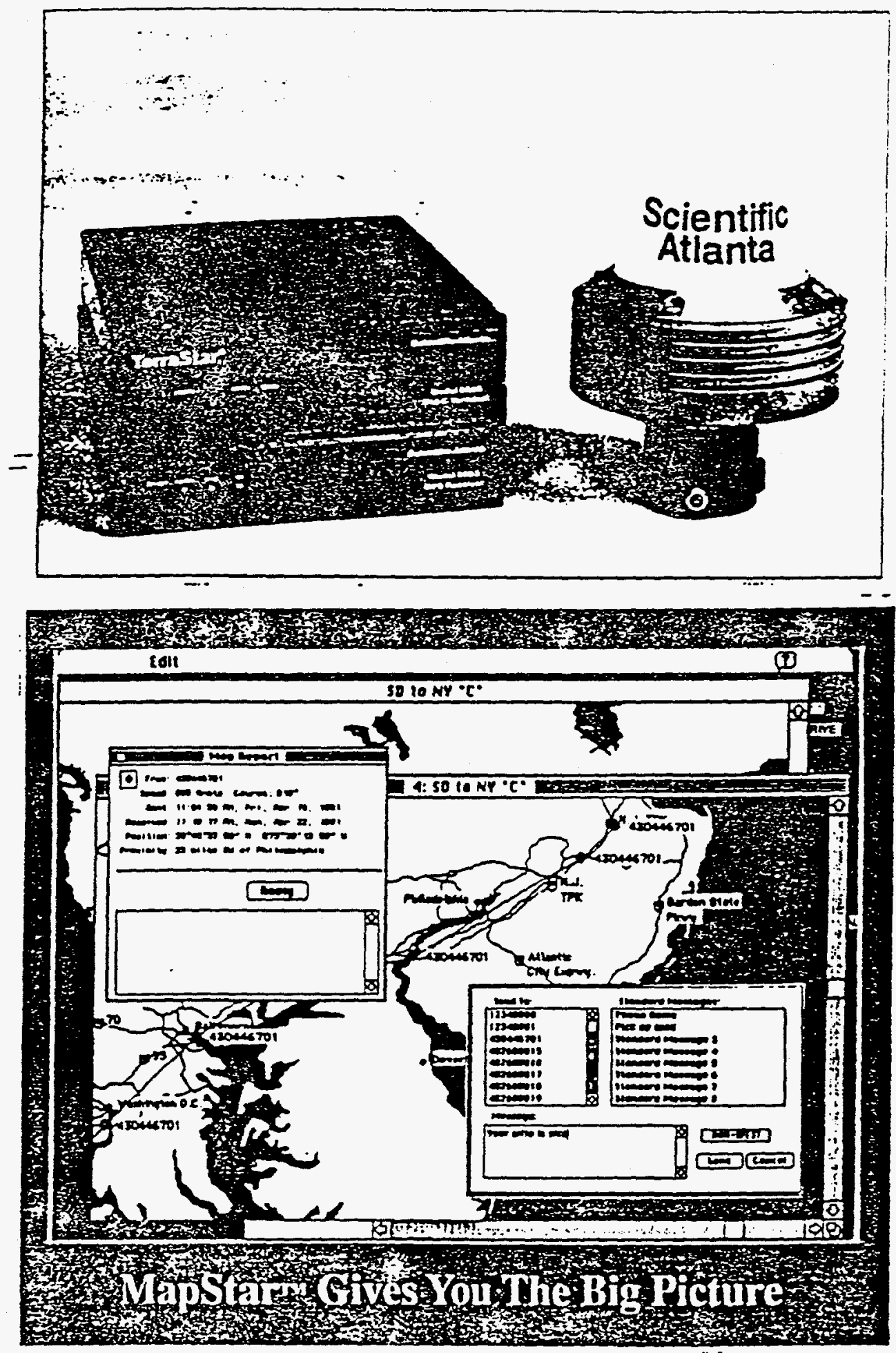

JPB2/27/93-6 
SPECIFICATIONS

- PROCESSOR OPTIONS COLOR DISPUAY OPTION

MONO DISPLAY OPTION

- HDD OPTIONS

TDD

- MEMORY OPTIONS

- VIDEO CONTROLLER

- PORTS

\section{- PCMCIA SLOTS \\ - SOFTWARE}

POINTINC DEVISE

INTERNAL MODEM

DOCKNC STATION

OTHER OPTIONS

WEICHT

SIZE

\section{BATTERY TYPE}

BATTERY LIFE

POWER REQUIREMENTS

ENVIRONMENTAL RANCE OPERATING

NON-OPERATING
$5 \times 125.0 \times 133.0 \times 2 / 50.0 \times 2 / 68$

TFT Color, 9.5" Dizeonal.

$640 \times 480.256$ Colors

STN Mono. $9.5^{\circ}$ Dheona $640 \times 480,64$ Shades of Grai

130/213/340MB

$1.44 \mathrm{MB}, 3.5^{\circ}$

4M8. (MB, 16MB. 20MB, $32 \mathrm{MB}$

32-bit Local 8us. Windows

Accelerator, 512KB DRAM

2 Serlal, I Parallel

External Color Monitor.

$640 \times 480$ (256 coiors)

$800 \times 600$ (256 Colors)

$1024 \times 768$ (116Colors)

Mouse/External Keyboard

2 Type II of 1 Type III

MS.Dos 6.0

Windows 3.1

Euilt in micro trackball

(16mm diametef)

$2400 \mathrm{~K}$ bps Madem with 9600 bps send/recelve tax, $14.4 \mathrm{k}$ bps Modem with 9600 bps sendirecelve fax

- 2 full Size. 16-bir ISA Bus Slots

- 2 Serial Ports, I Parallel Port

- External vea

- 40 Watts Power Supply

Docking station, external Battery charger. car adapter

$6.38 \mathrm{lbs}$ (2.9ke) with battery

$11.1^{*} \times 8.58^{\circ} \times 2.00^{\circ}$ (colon

$(282 \times 218 \times 51 \mathrm{~mm})$

$11.1^{\circ} \times 8.58^{\circ} \times 1.77^{\circ}$ (mono)

$(282 \times 282 \times 45 \mathrm{~mm})$

NiCad / NIMH

$2 \cdot 3$ hours

Voltage: $115 \cdot 230 \mathrm{Vac}$

Frequency: $50 \cdot 60 \mathrm{~Hz}$

Temp: $50^{\circ}$ io $95^{\circ} \mathrm{F}\left(10^{\circ}\right.$ to $\left.35^{\circ} \mathrm{C}\right)$ Shock: 50

Vibration: 1.00 peak, 3-200 $\mathrm{Hz}$

Temp: $44^{\circ}$ to $140^{\circ}$ \& $\left\{20^{\circ}\right.$ to $60^{\circ} \mathrm{O}$ Shock: 600

hbration: 1.5C peak, 3.200 $\mathrm{Hz}$
The Austin 486 notebook is

architecturally the most advanced on

the market. Designed to fully utilize the entire family of powerful Intel 486 processors, Austin's notebooks pack all the speed and power of the best desktop workstation into a compact, light welght case. A unique 32-bit local bus video, with a windows accelerator, creates the best notebook graphics performance available. Technolotically advanced, high-performance, glass media, hard drives, in sizes yp to $340 \mathrm{MB}$. set the industry standard for storage. The color models feature an active-matrix display providing crisp, clear color while running a CRT and the LCD simultaneously for impressive portable presentations. The large $16 \mathrm{~mm}$ trackball, located front and center, affords optimal comfort and control. Two PCMCIA slots support two type II devices or one type III device at any given time. This 6.38 lbs. powerhouse gets you up and running while you are up and running.

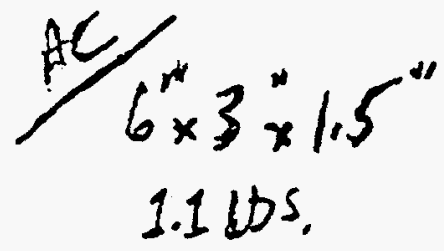

* I ye warranty PÉl
* 30 Monky Brate

CALL TOLL FREE: 1-800-752-1577

CANADA: 1-800-338-1565 - INTERNATIONAL: 512-339-3500 - FAX: 512-454-1357 


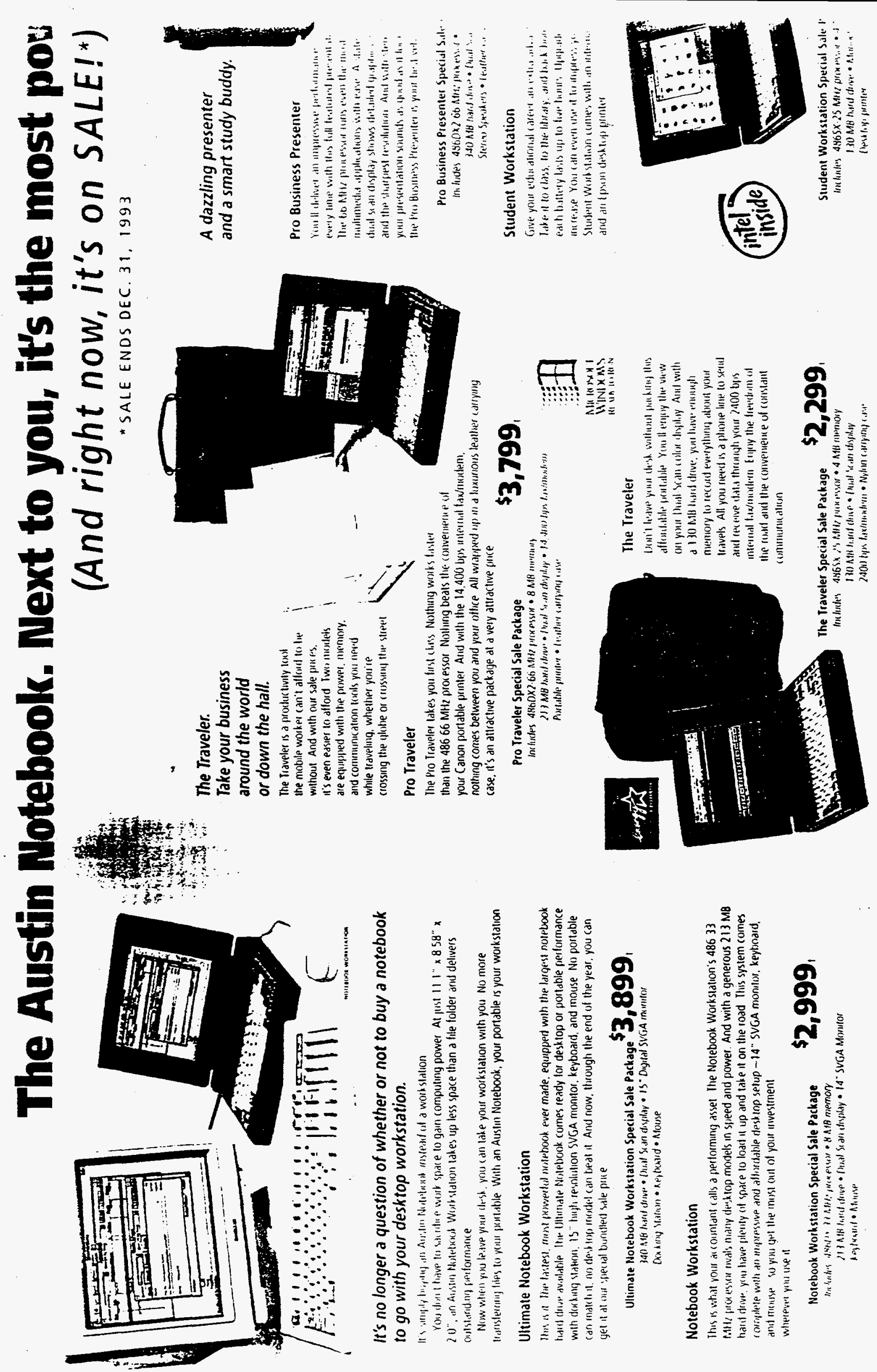




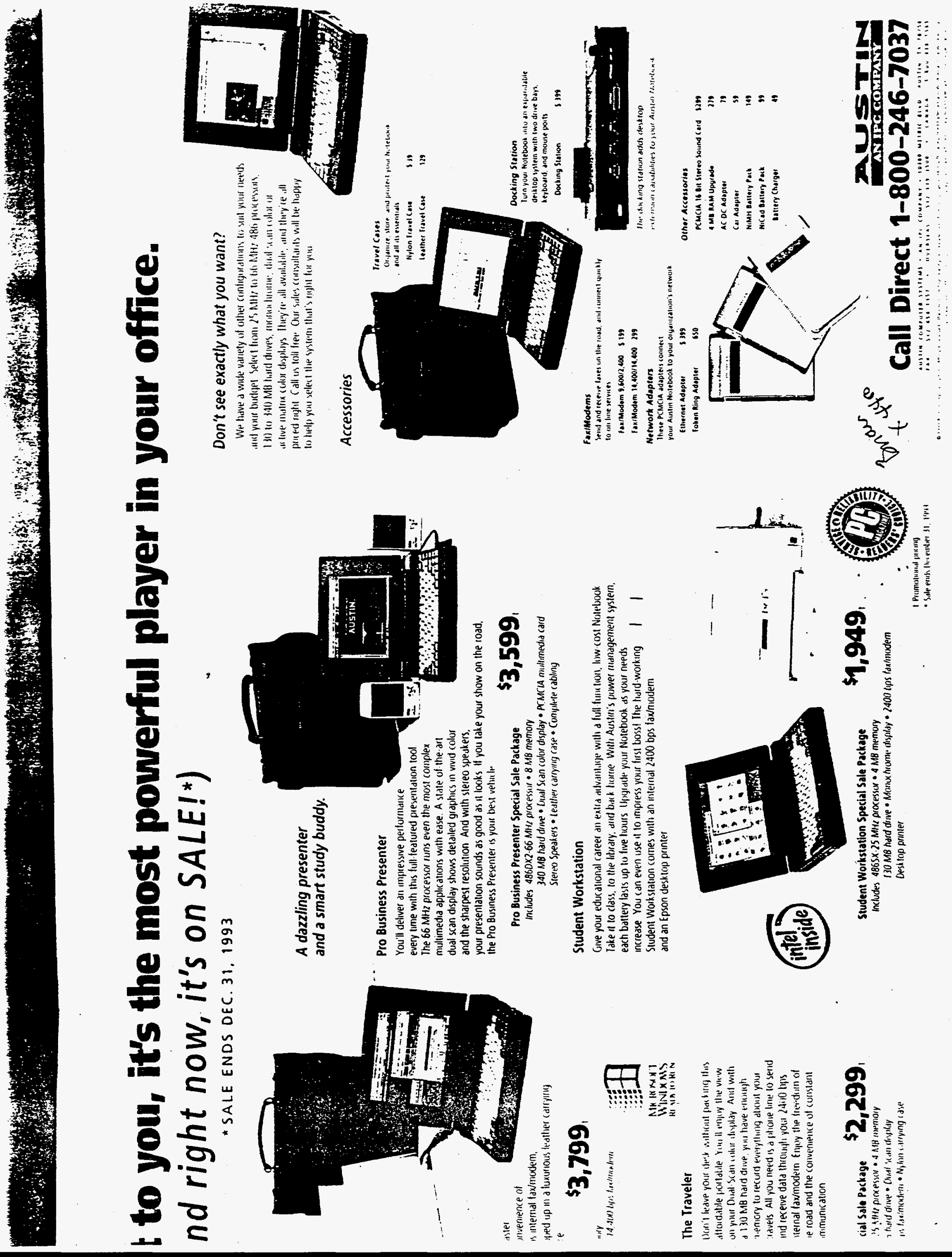




\section{Clear your desk}

\section{before it's too late.}

Does your computer have more room to work than you do?

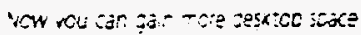

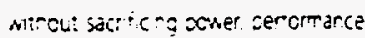
zomor hrerer you reeg a tover

ot zower of a $\operatorname{cac} x+c-5 c+00$ casic. we rave an Awsir hotecock 'cou A-c inroug̣r Lecemaer 31 icl gar save or szec al kc:encex zurcles cescred :0 zerver :re grejas: aide at we chest once

\section{Let's make a deal.}

2ustin's suber seection of Notedooks stars with

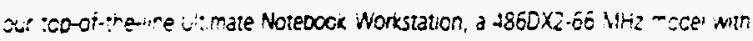
a $\$ 40 \mathrm{MB}$ haro zrve its not onty the sest cortable in Austh, ts the zest acrasie.

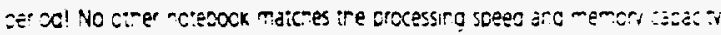
$\therefore-0$ no cesk:co rocel can seat $t$

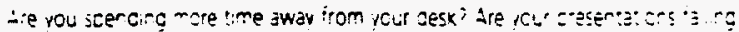
:a:" Nould a ocrable out you dt tre nead of tre class? Ne nave roce's "ir you. :oc

Ano if we naven: mace vour aream macrine, we il iet vou rake rcur in? jusi ma and match the features you want and onone in your order. See ns.ce cor "butid-your-own" ae!ais.

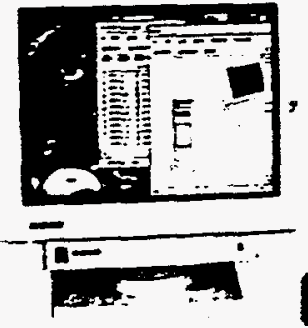

The best of both mortds Connect your votebook to a arge-screon

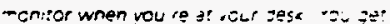

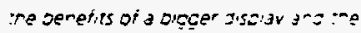
acuantages of a nign-cemorm,ms: zcraz' $\epsilon$
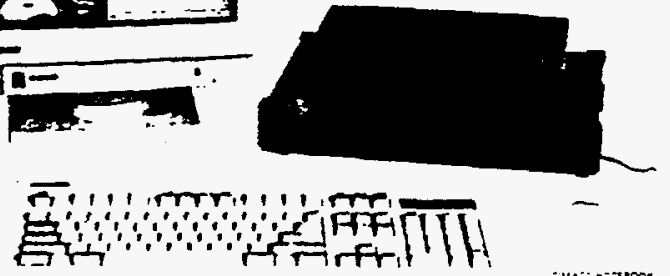

$-$

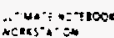

\section{Here's what you get with an Austin Notebook!}

- Lightning-fast video-rout oresentations izeren ire ocwer ji our j2-br local-ous viceo jeteerdior win I GB Video RaM. Ano with mit:areous outout to an exernas monitor. you in srow off rour jnow in the office, in the : assiocm, or on the rado.

- Your choice of displays-Choose a too-oi-tre re acive Matrix dasolay ior the most demanaino $\therefore$ cr aopications. Get cost-ffectre coior with a

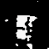
- Suai-ican atsolay or oot for razor-sharo resolution wis uur diforsadie monochrome disolay

- Peak performance-zusun Notebooks run on Irier s sowernouse 486 orocessor. You can cnoose the evet of oeriormance and speed vou want-irom SX :0 DX2 ara irom 25:0 $66 \mathrm{MHz}$. Even at top soeeds. uur rieçrateo coolng system keeos iemperatures under sontrol.

- Ample storage- ur fucceo naro arves eajture glass-meala construction. Load vo win 130. 213 or $340 \mathrm{MB}$ - the arges: trues on the market?

- Future expandability-4cc-on seires iwo voe d er ore yce thi giug instanty nto

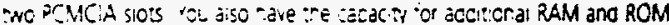

- Auto stop-jre socr au's vour sysier :0 5:ancev Mode mo dack into acive

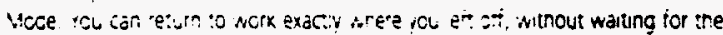
irstet to Doot.

- Sophisticated power management- ital g000 is a acracie if you re lieg io a power source? Ausin Notesocks lse ess energy. our oattenes las longer, ano you ave more time to work tor playl unoiugaed.

- Energy efficient operation-Ats:in Notedooks Tee! EPA Energy Star "gurdelines orovaing the pull oower of a desktop system at ony a raction of the efectricity. is sood for the envronment, and it's good icr vour octtom the.

- Strong service and support-Ausili orovices iree exser consultation. lifetime toll-

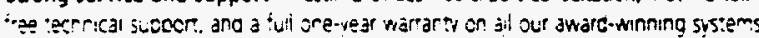

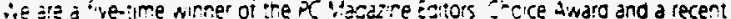
-

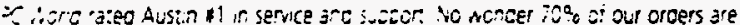
rom esceat customers.

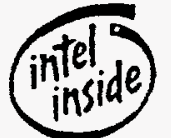

2avstrin Call Direct 1-800-246-7037 


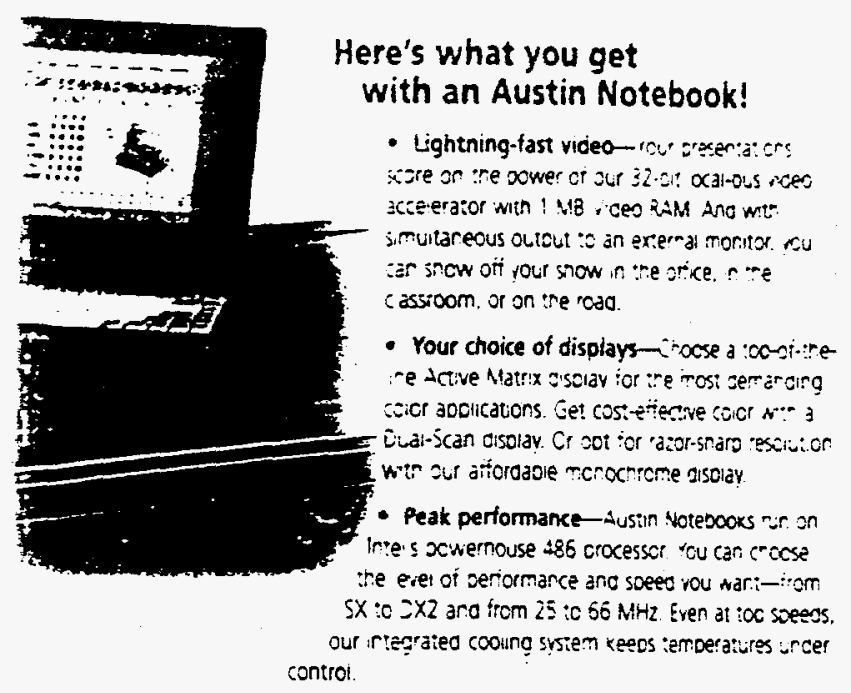

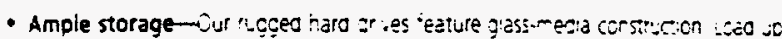

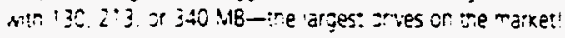

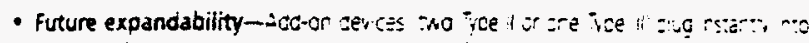

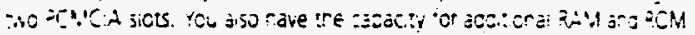

- Auto stop-Ore touch outs your sys:em nto Starcoy btoce arc sack ritc Acre Hoce ycu can return io work exactiy anere you eri zi. winout Nating ior tre sysiem :c soot.

- Sophisticated power management-what zood is a sortabie if iou ie :ea to a

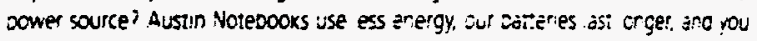
have riore time to work ior play) unciugced.

- Energy efficient operation-Austir vctecocks meet EPA Erergy Siar guicelires.

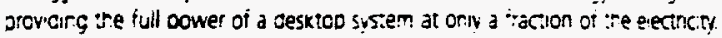

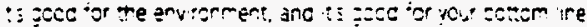

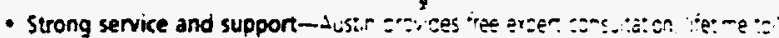
"je :ez-cal siccor. jro 3 :

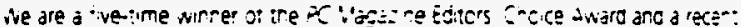

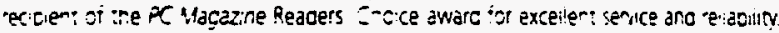
$x$, icre ates Austin 1 ir sernce j-a sucoon. Aic norcer $76 \%$ or our ersers are in- ecejt: s.stomers.

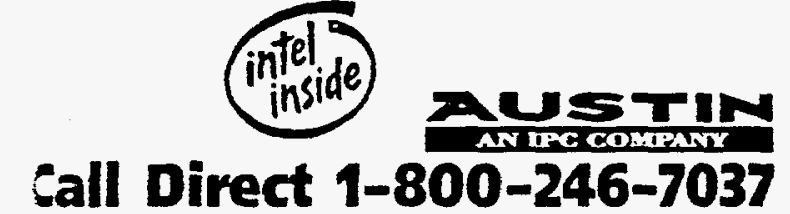 \\ Call Direct 1-800-246-7037

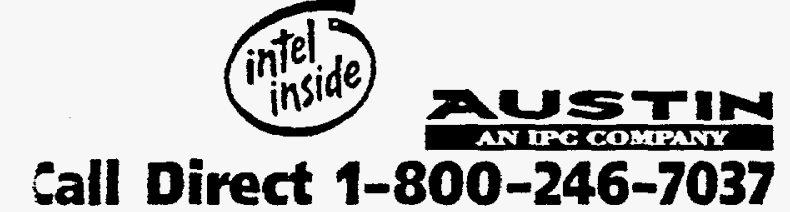 \\ Call Direct 1-800-246-7037}

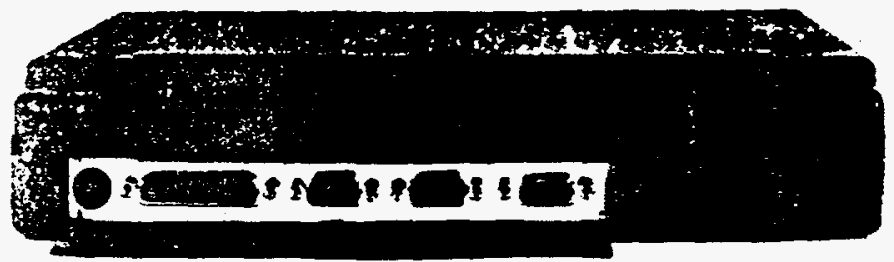

Specifications

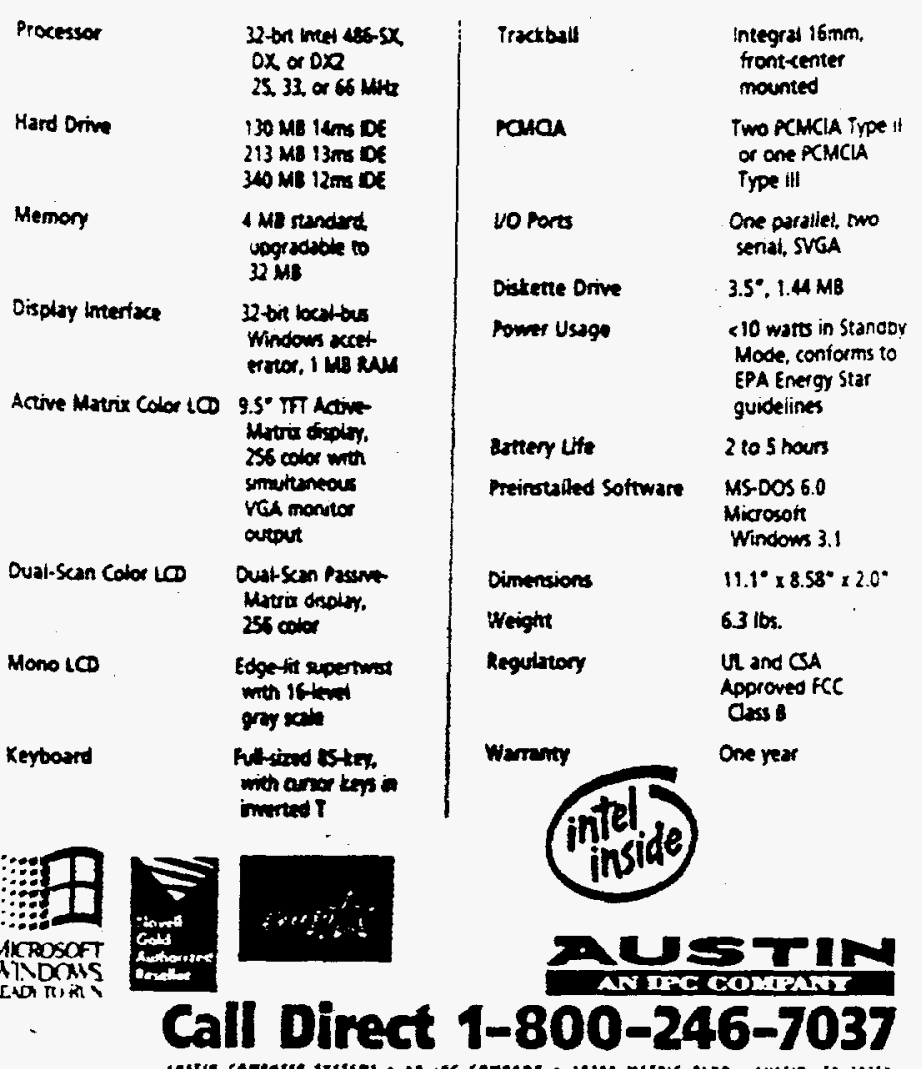

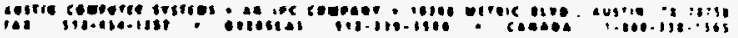

-

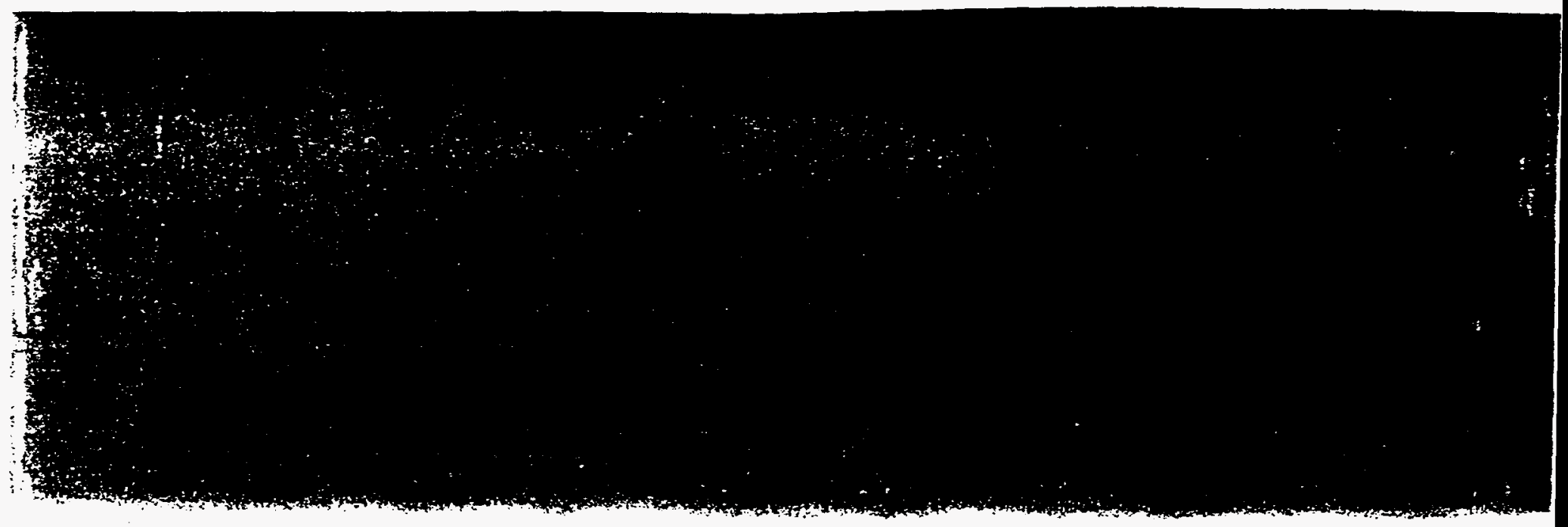



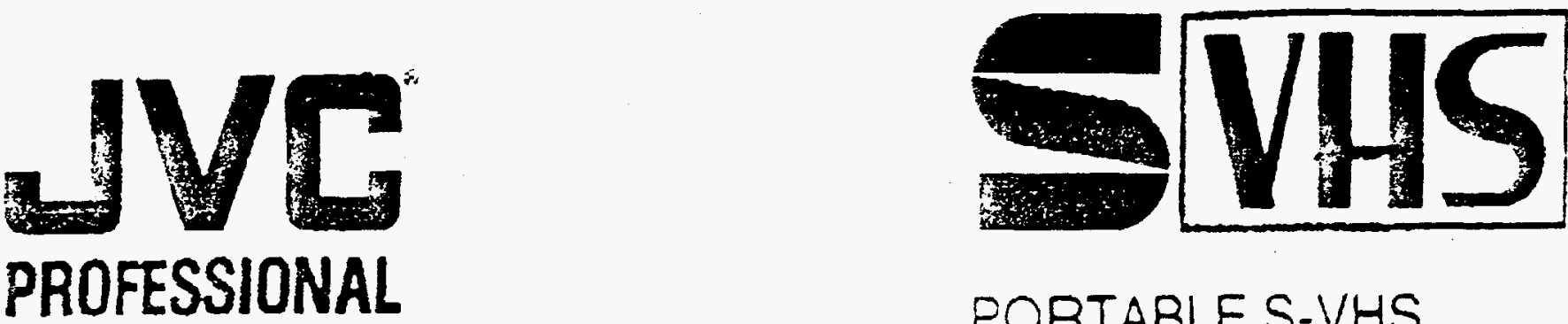

\section{PORTABLE S-VHS RECORDER}

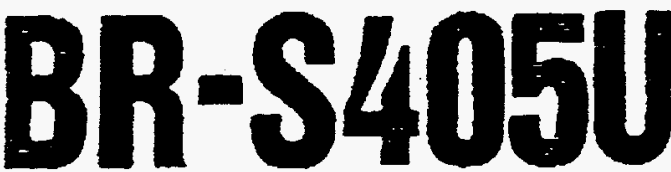

A separate portable professiona! S.VHS recorder ideal for use $\therefore$ th any existing stand-alone camera.

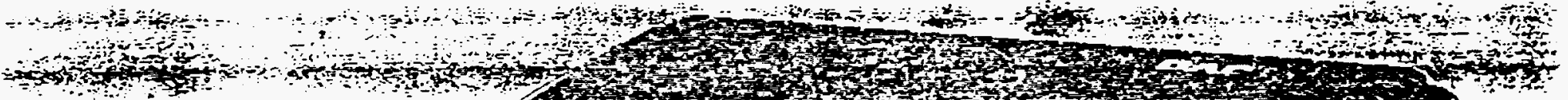

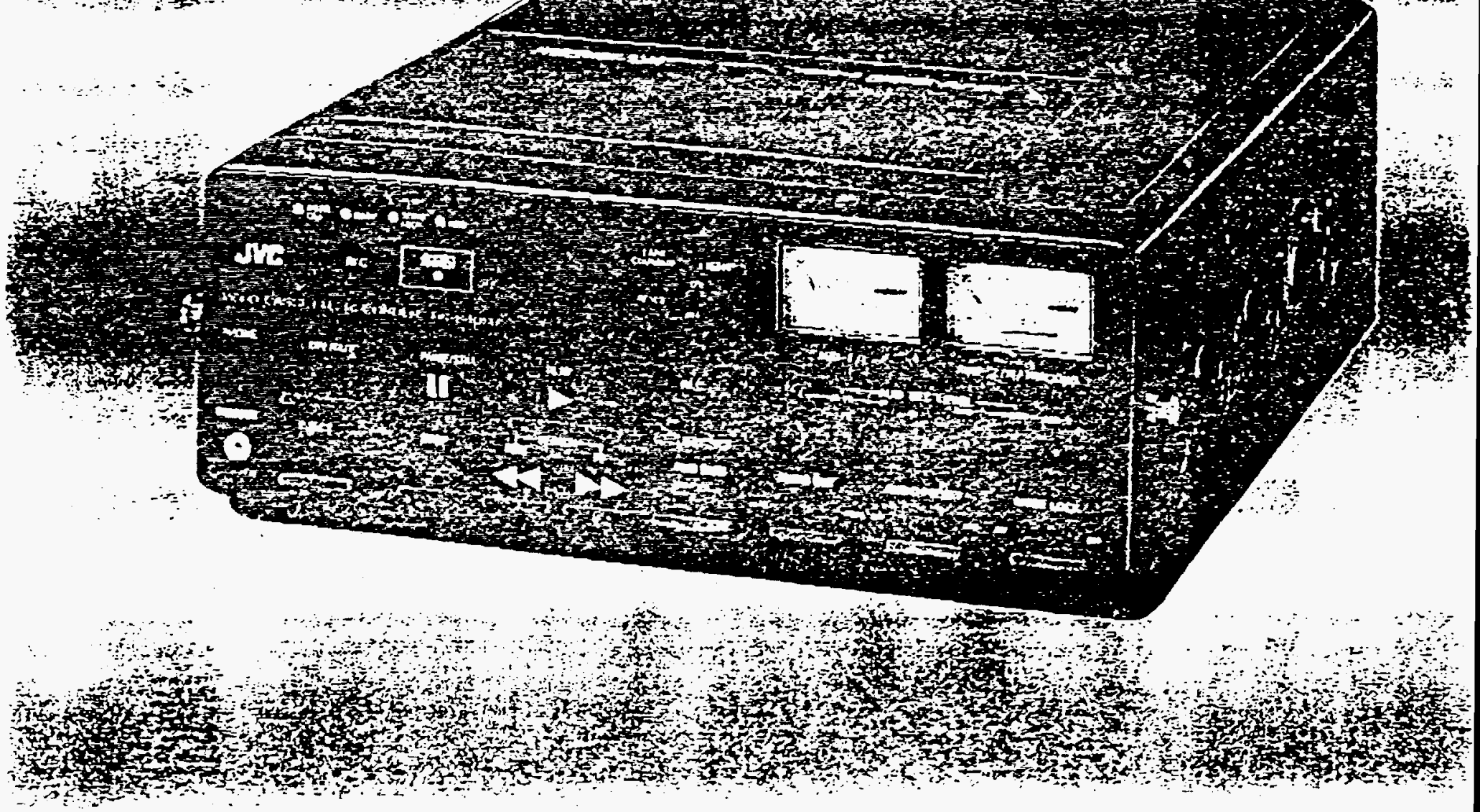




\section{IF YOU DON'T NEED A CAMCORDER, WHY}

JVC'S 8R-S405U Portable S-VHS Recorder is Designed Exclusively For Use In Separate System Configuriations

Not everyoody w/10 llecids a portable recordet. needs a camcorder. If you prefer a separate system - whether it's for long-duration on-location shooting or it's because your assignment requires you to mount the camera on a dolly and the recorder on a cart - then why compromise with a recorder that's not really designed to do the job? For maximum efficiency and pornfessional results. you need a portable recorder designed specifically for separate use. You need JVC's BR-S405U Portable S-VHS Recorder. Free from the kind of design characteristics that can make a dual-purpose (dockable/portable) recorder less than ideal for use as a separate system, the $B R-S 405 U$ leatures optimally positioned controls, easy connection to any existing camera, plus a handy mode lock function and an audio preset switch to ensure worry-free operation in any situation.

So when you need separate sysicm vortatility. don't compromise. Choose the recorder that's designed to do the job. The BR-S405U. With its superior S-VHS picture quality and Hi-Fi VHS stereo sound. full range ol professional leaturcs, and separate system flexiblity, it'll make it easy for you to get the job done right.

\section{HIGH-QUALTY PICTURES}

Hign-quality S-VHS pictures

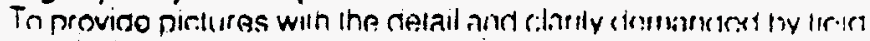

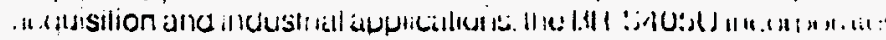
-VC's advanced S-VHS lechnology for high-qually piclures; with resolution of more than 400 lines. VHS recording is also avaiiaode.

Bulli-In chroma nolse reduction To further improve picture quality, an advanceo ALU (Aulomatic Level $\cup p$ ) recording circull is used to improve the chroma signal-to-roise ratio. This inlusticaied sysicm incruasus ignal ievel and color burst in recording, then reduces ine signal to its original tevel in playback, thus maintaining the onginal chroma level while requcing chroma noise.

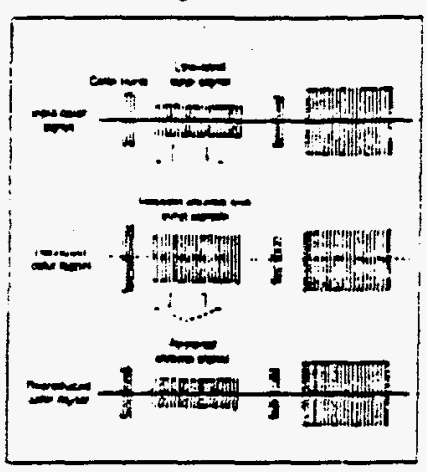

Separate Y/C Input and output

In addition 10 permitting connection with any existing carnora. ino BR-S405U's 14-Din camera connecior can accepl separalco $Y / C$ signais. making it possible 10 build a high-quality field iarquisition system by combining the BR-S40.5U with a prolessional carmera equipped with separate Y/C output Auct. lis

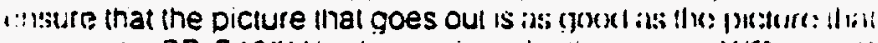

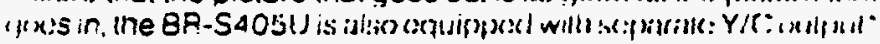

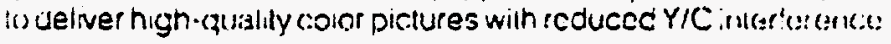
Reduced jitter

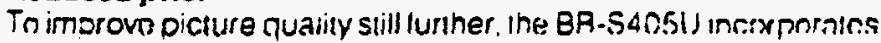

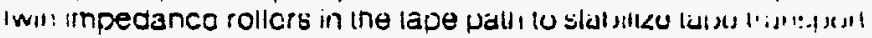
inis greatly red ces jitter components to onsure a c:ear. stable pici.ure

Rotary ersso heads and AEF function

A vair of rolary erase heads are mountec on the head dr um lo i:nsure clean, prolessional-quality recording? Jir ing

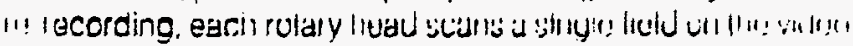

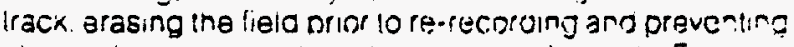

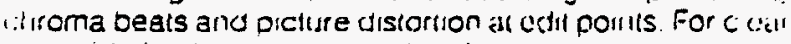
assemble eating with no overlapping, autorralic backscacirg s provided by the AEF (Automatic Editing Function) mechanismi.

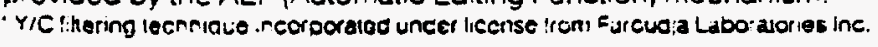

$\therefore 1$

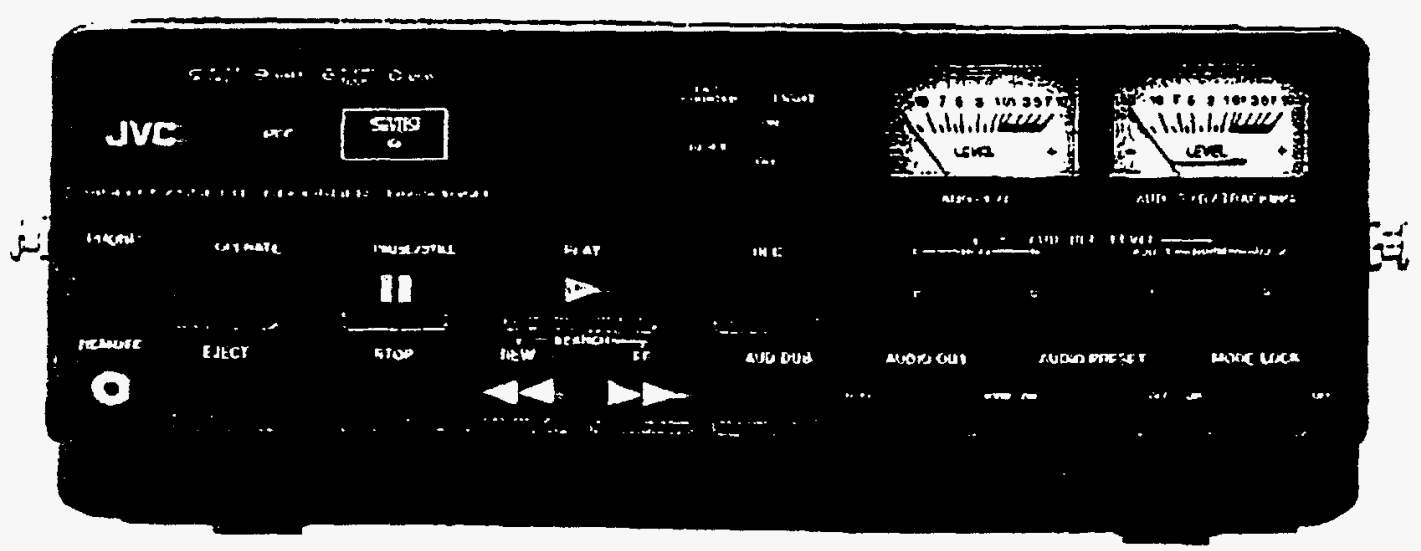




\section{HIGH-QUALITY SOUND}

\section{Hi-Fi Stereo sound}

Using iwo rolary FM-audio heads 10 rocorr $\rightarrow$ Fi ausio signals

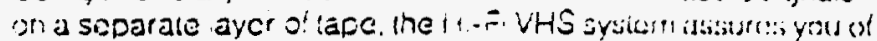
5uperto sourd qually with exienpeo treo_ency essorsu dol $20 \mathrm{~Hz} 1020 \mathrm{kHz}$. a dynartul: rangge : $\mathrm{n}$ excess of $80 \mathrm{db}$ and minima wow and fiulter. $A H_{1}=$. REC switeris provided :c delea! reccrding on ine Hi-Fi !rack

\section{Bolanced XLR Input connectors}

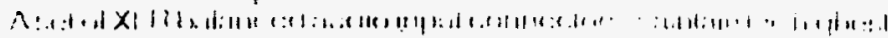

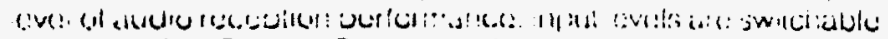

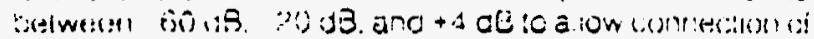

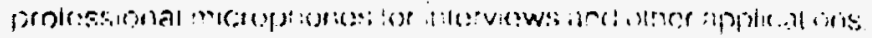

Audio Presel switch

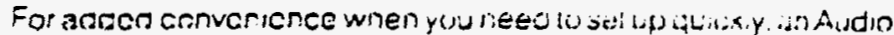

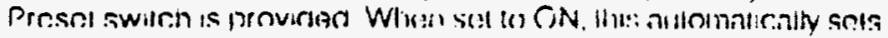

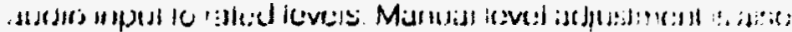

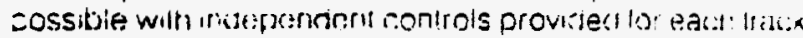

Audio Dubbing

The BA-5405U's slereo nerrai juclo track lealures dickobutung

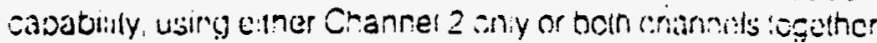

\section{MOBILTY}

\section{Large AEC indicator}

A large red REC ndicalor lorated on ine RR.S40SU's lion: pane vilins during recording, illsking visual conilrmalion ol recoraing casy even finm a तislance.

\section{LCD lap timer with 10-hour memory backup}

The 8R-S405U's 4-dght iape counter car de swilched lu a 5-digit :ap timer oisdaving elansed lade imo n hou!s. -inules.

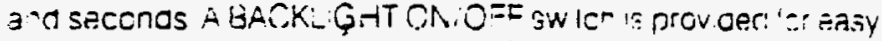

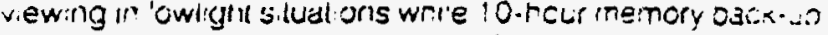
ensures contnued accidacy crom after power swilch-oll

\section{Augged construction}

To meet the iggorous demanos made on a norlable orduss onai

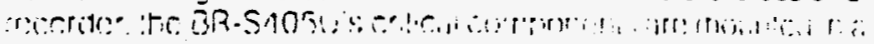

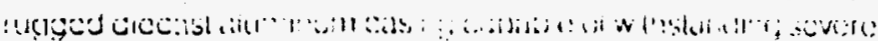

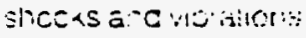

\section{RELLABILTY}

Mode lock function

When you want !o pievent accidental or deliberate mishanding of the recorce! s controis, simpiy set this switch to ON altcr setting all recessary controls. You'll be able lo concenirale on camera oderations wilnout worrying aboul mishads. Especially convenient in situations where you can't keep a close eye on the 'ecorder of have to leave it unantended in a crowded area.

\begin{tabular}{|c|c|c|c|}
\hline & & & HOUR METER \\
\hline ON & Allo $-?$ & ON & S= \\
\hline OFF & $\begin{array}{c}\text { AUD-1 } \\
+ \\
\text { AIID-2 }\end{array}$ & $\begin{array}{l}\text { OFF } \\
\qquad A E F\end{array}$ & 0 \\
\hline
\end{tabular}

\section{$2000 \mathrm{H}$ hour meter}

To facilitate scheduling of mainienaince, a meter is urovidual which shows operatirg time up to 2000 hours.

Comprehensive warning system

To ensure trouble-free operation ano minimize downtime. LED indicaiors warn of problems sucn as servo lock lailure. depleted battery. condensalion, and automatic shul-off due 10 ralunctioning tape transport. An audible warning is simultanenusy oulpui from the eatohone jack.

\section{AV output terminals}

In addition to Y/C 358 oulpul, the BR.S405U is equipped wilh composile video and 8-pin AV outputs. Independent $1 / / R$ audio output ferminals are also provided.

High-speed shuttle search

For more search flexibility in the field or in the studio, shumte search al 7 imes normal speed in either direction is possible.

\section{Large backilt audio level meters}

For easy mon:toring of audio levels even in dark or dimiy-lit conditions. two large dacklit VU meters aie provided.
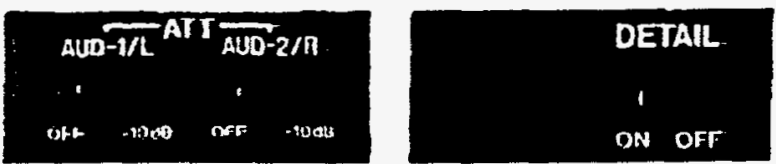

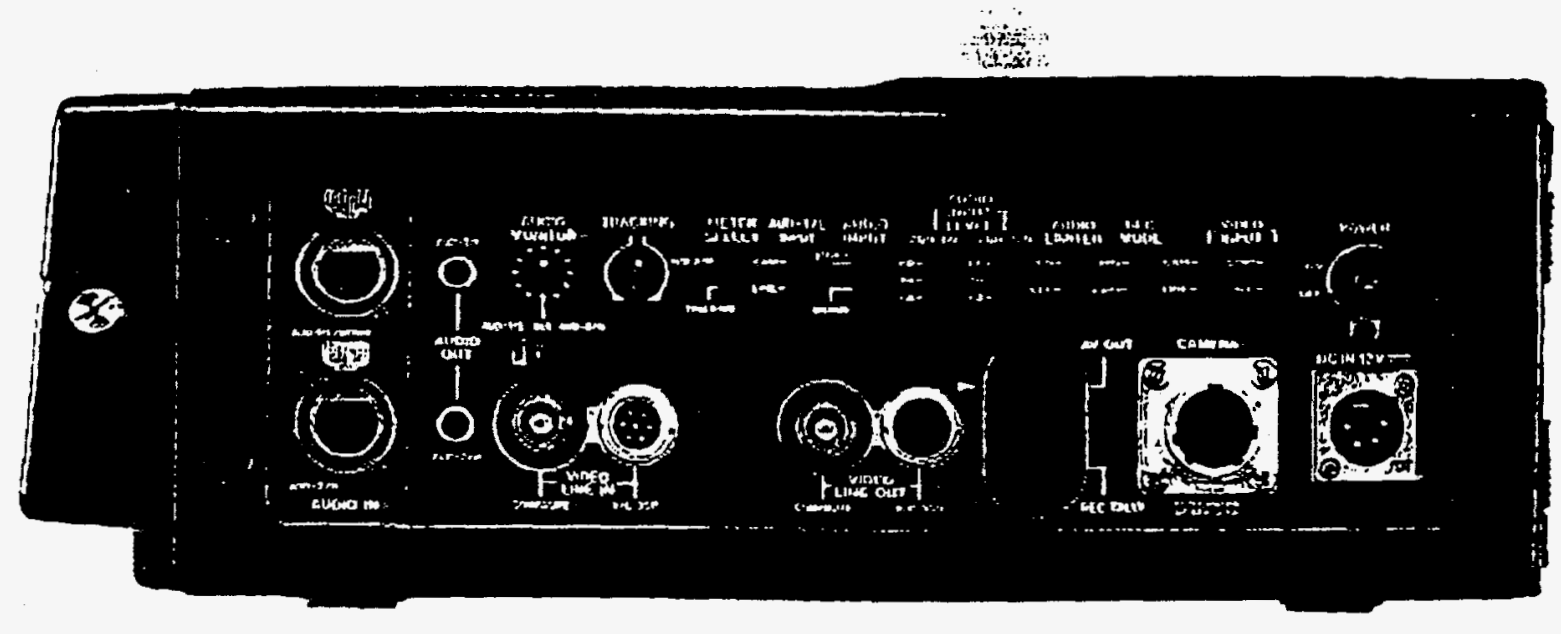




\section{SPECIFICATIONS}

Format: VHS/S-VHS siandard

Pecording system: Luminaned FMrnrorting

Color Sown-romwerted j.incurries

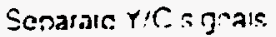

Signal sysiem NIRC:

Tape speed: 33.3 . 1.merr:

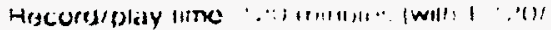

S: 120 casclic

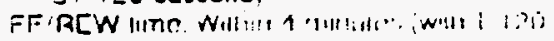

$$
\text { 1...i.:.:th:! }
$$

Power source. : $; \vee 100$

Powet consumpion "I W

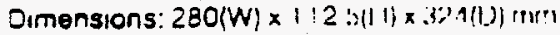

$11: 1 / 16 " \times 4 \cdot / 111 \% \times: 2 \cdot 13 / 96 " 1$

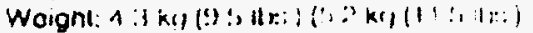

win NB.G IU arid laptel

Opernting temporalure: $0^{\circ} \mathrm{C} .10 \mathrm{~A} 11^{\circ} \mathrm{C}$

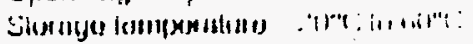

Video

Indul: a 5 in 20 Vir-n 73 urms. undalanced

Oulnut: : i VD.D. 7 'j o'r.s. urpatanced

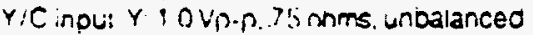

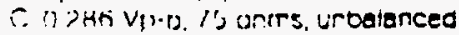
$(1+1): 3$

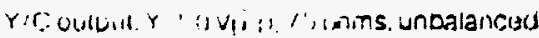

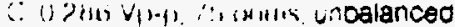
(in $1,1 \cdot 1$,

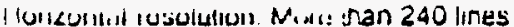
ivils (c) (b)ext)

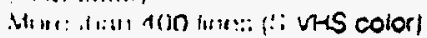

S.N ratuo At afi $[S-V+1 j]$

1:) (UA IVHS) (Uelz" SW OFF)

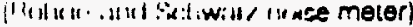

\section{Audto}

Number of channois: ? Hi-Fi channe's 2 normal channels

input: -60 o8s $(3 k$-onms $) /-20 j+4 d 8$ s

(10 k-onms). malanced (HI-Fi and i*ormall

Cutoul: $-6 \mathrm{dBs}$. $1 \mathrm{k}$-ulm. unbalancen

(Hi-Fi and normill)

Hesoonone oulpul: $-4510-25$ (165. if $131 \mathrm{~mm}$

HifFi audio

Frequency rosponso: :011/ : $: 010(3) 1 \mathrm{l}$

Dynamic range: Mori inan $80 \mathrm{aB}$

Wow \& fluther: Willin) $0.007 \%$ WRMS

Normal audio

Frequency response: $40 \mathrm{~Hz}-: 2.000 \mathrm{~Hz}$

SIN ratio: More Ifian AA IIA

Wow \& fluter: Willm 0.25\% HMS

Accessories: Carrying nandin $\times 1$, Shmulder

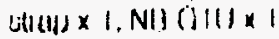

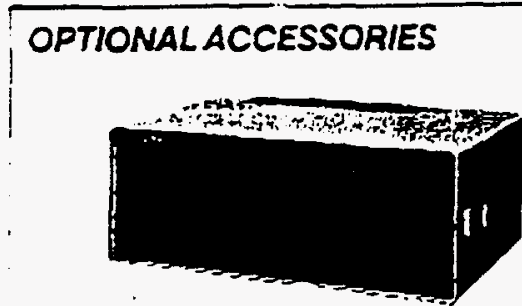

AA.G10U

Battery ChergoriAC Power Adepter Charges four NB-GIU battery ixicks

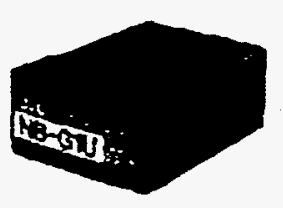

NB-G1U

Rechargenolo Baltery Pacx One NB-G $L$ is provided wint the

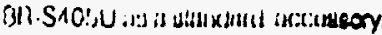

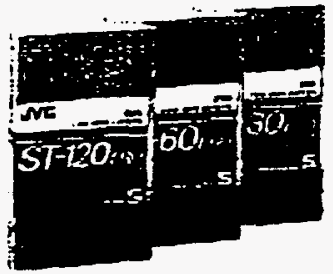

Professional-S Tapes

ST.120paOl2 rours recoruling)

ST-6OPRO (? neas ee:nidulu!

ST-30PRO 130 minules recerraing|

Hign-pariormarce S. VirS tuve

with increased 8 , rad. lity anci

'thgher-censiy magnelic

particles sesigneo esoectaliy

for professicnal use

\section{DIMENSIONS}

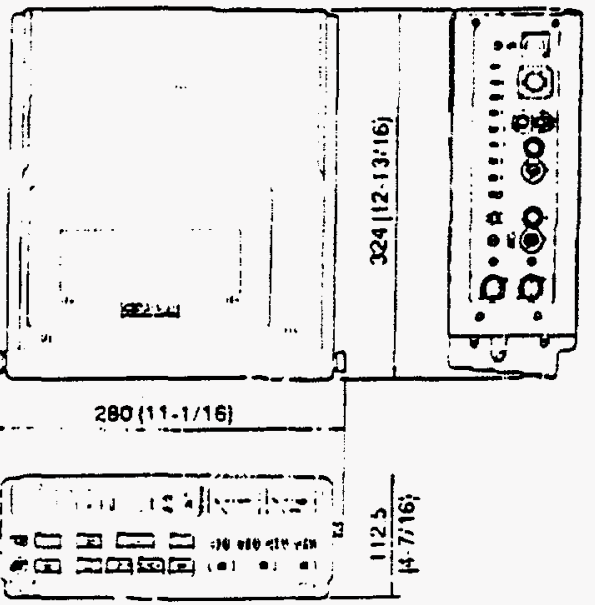

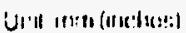




\section{Model D5200 DSR MPEG Encoder}

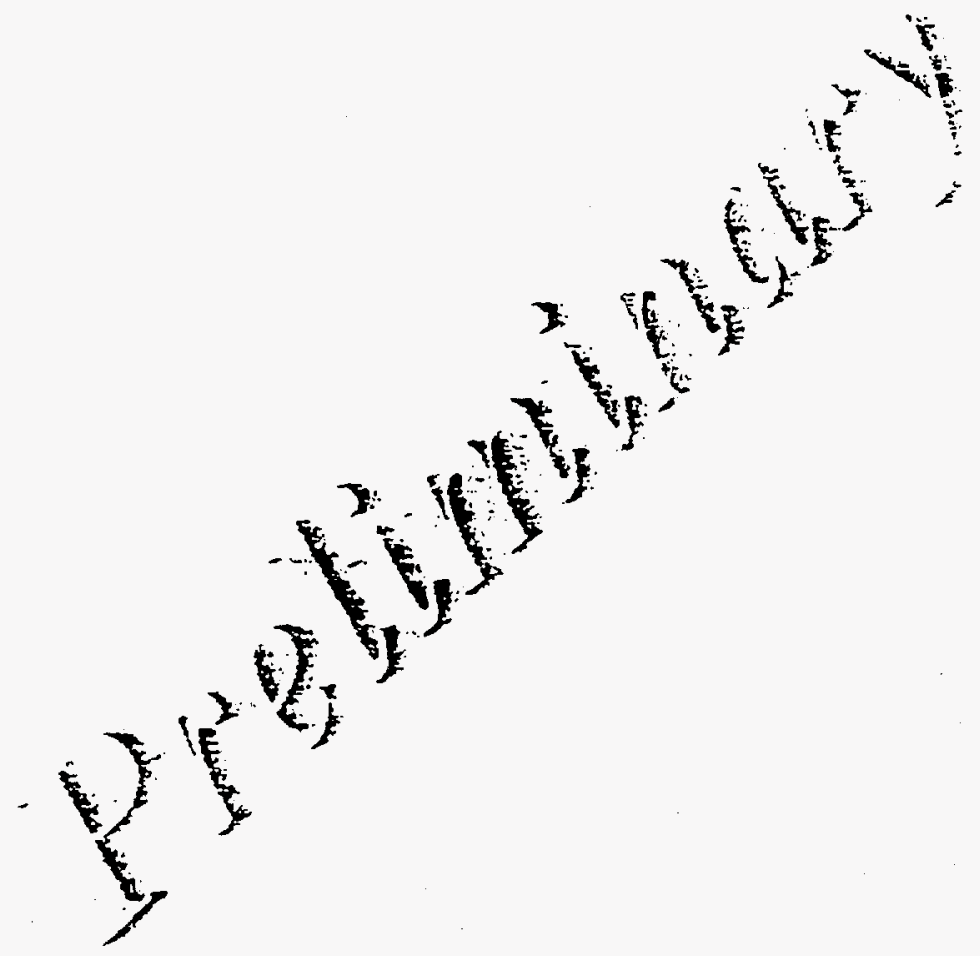

SCEEVTFIC-ATLANTA, INC. PROPRIETARY INFORMATION 


\section{Technical Specifications}

\begin{tabular}{|c|c|}
\hline Power & $\begin{array}{l}\text { A aulomatic seasing Universal Inpur accepaing } \\
98 \text { to } 240 \mathrm{VAC} \text { as } 50 \text { wo } 60 \mathrm{~Hz}\end{array}$ \\
\hline Size & $\begin{array}{l}177.8 \mathrm{~mm} \text { (7.0 in.) bigh, } 483 \mathrm{~mm} \text { (19 in) wide } \\
533 \mathrm{~mm}(21 \mathrm{in} .) \text { deep }\end{array}$ \\
\hline Weight & approximacely $9.1 \mathrm{~kg}(20.0 \mathrm{los} \bar{x}$ \\
\hline Storage temperature & $-20^{\circ} \mathrm{C} 10125^{\circ} \mathrm{C}$ \\
\hline Operating temperature & $0 \times \mathrm{C} 1040^{\circ} \mathrm{C}: \because$ \\
\hline Oporating humidity range & teso tQ $90 \%$ con-condeasing \\
\hline \multicolumn{2}{|l|}{ Video Ericoder Board } \\
\hline Resolutition & $704 \times 48030 \mathrm{~Hz}$ NTSC \\
\hline Bit rates $\quad \therefore$ & $5.3 \mathrm{Mbps}$ - $8.3 \mathrm{Mbps}$ \\
\hline Elt stream protocol & MPEG Video Layer (CL950 Comparable) \\
\hline
\end{tabular}

Video Input Board

\begin{tabular}{|l|l|}
\hline Video input & NTSC (RS I70) \\
\hline Video inpert loval & IV p-p $\pm 1 \mathrm{~V}$ \\
\hline Input impedence & $75 \Omega$ \\
\hline Input return loss & $20 \mathrm{~dB}$ \\
\hline Input connoctor type & BNC \\
\hline
\end{tabular}


MPEG Audio Encoder Board

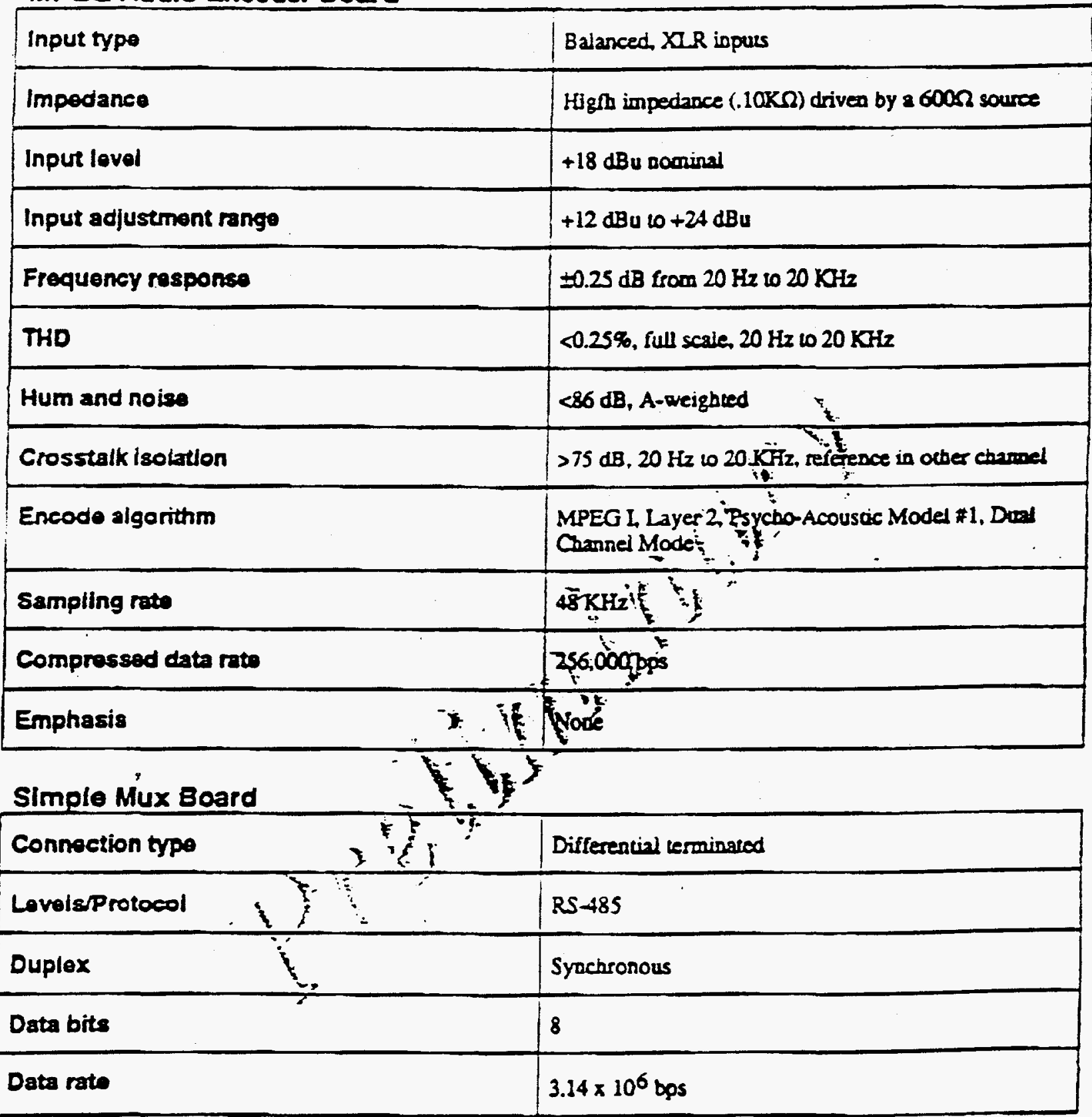


Serial Data - Status/Control link

\begin{tabular}{|l|l|}
\hline Qsud rate & 57,600 \\
\hline Parity & No Parity \\
\hline Data bits & 8 \\
\hline Stop bits & 1 \\
\hline Duplex & Half Duplex \\
\hline LovelsProlocol & RS-232C \\
\hline
\end{tabular}

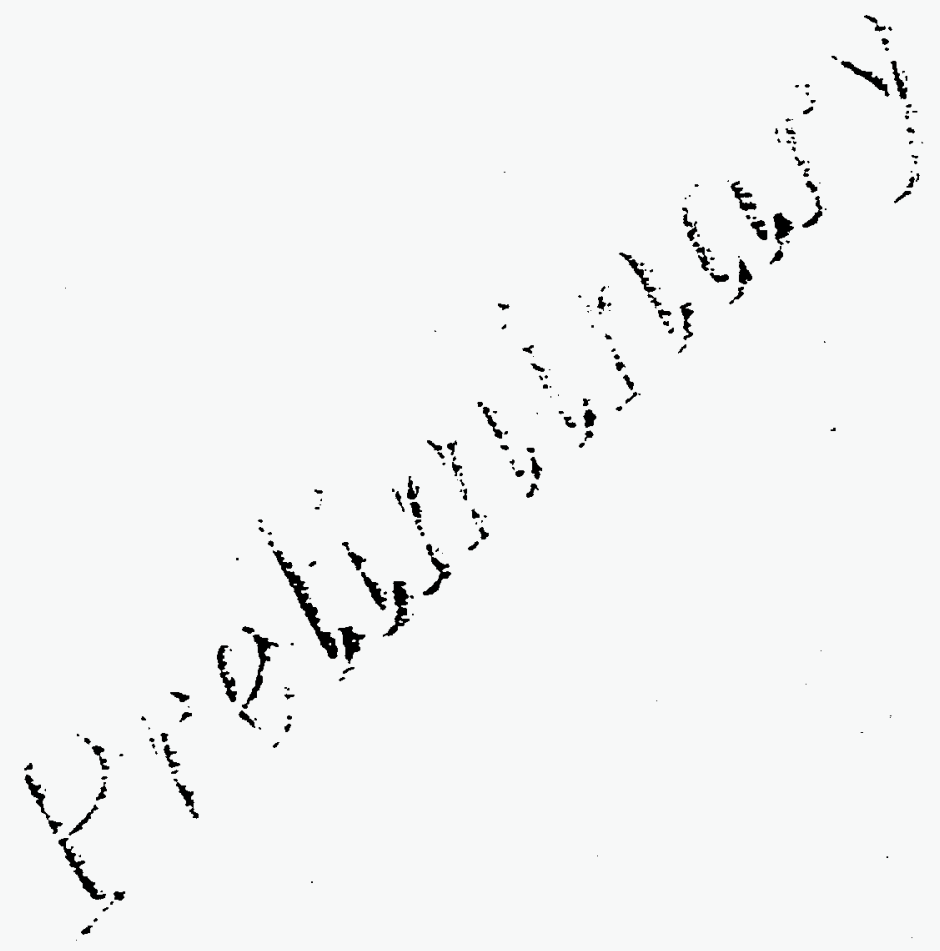

\section{SCIENTIFIC-ATLANTA, IMI. PROPRIETARY INFORI I I: :}




\section{Scientific Atlanta}

Scientific-Allama's MapStar ${ }^{\mathrm{TM}}$ Auromatic lehicle Location (AlL) softwar package provides the dispatcher interface for fleet communications and tracking. Utilizing the global satellite system. Inmarsat, a consortium of 65 countries. MapStar ${ }^{\mathrm{TM}}$ is connected with ScientificAtlanta's MariStar ${ }^{\mathrm{TM}}$ or Terrastar TM products to provide real or near real time two-nay communications between the dispatch office and mobile vehicles anywhere in the norld.

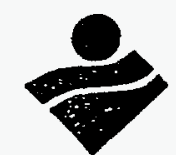

INMARSAT System Provider

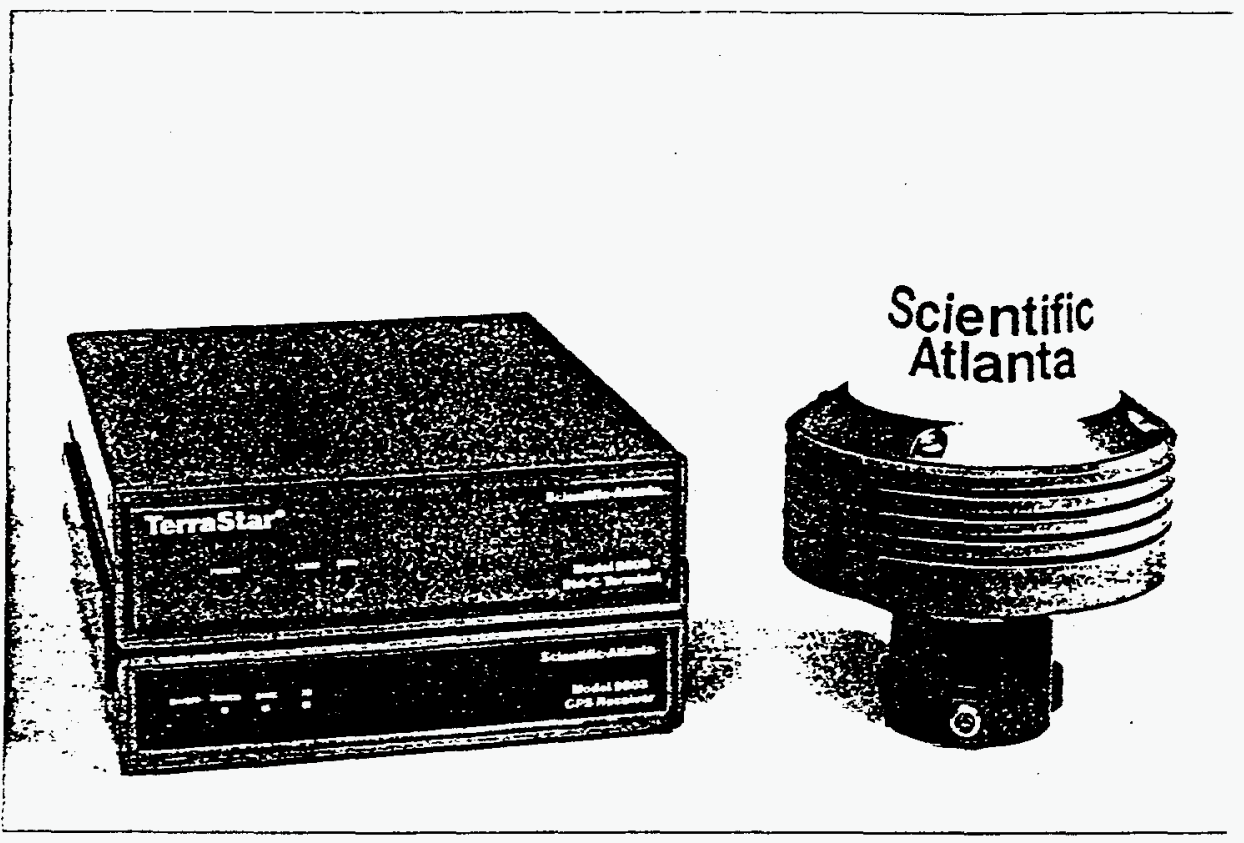

Scientific-Atlanta's TerraStarim -CMariStarim -C Terminal is one example of an Inmarsat Earth Station that can be used to communicate with the mobile vehicle/vessel using MapStar' ${ }^{\mathrm{M}}$.

\section{Features}

MapSlar'T has a number of flexible features including:

- Vehicle/Vessel Tracking for Entire Fleet

- Cartographic Flexibility

- Variable Communications Interface

- Two-way Communications

- Stand-alone Configuration

- Front-end Communications for Midrange and Mainframe

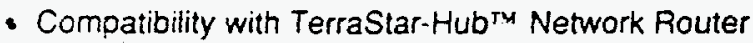

\section{Description}

MapStar is is a graphic display, communications, and database management system for vehicle tracking applications. Users will be able to track vehicles. send and receive messages, establish data communications, and obtain vehicle status reports.

Vehicle locations are displayed on maps, which may be customized to the user's specific requirements, providing an interface for the user to the map display and two-way communications. Using MapStar rm, the dispatcher can monitor in real time the location, speed and ETA for all vehicles in the fleet, and send and receive messages.

Scientific-Atlanta, Inc.

Fax - 404-903-5346 


\section{Full Features of MapStariM}

Vehicle/Vessel Tracking

- Receives position data and plots vehicle's exact location on map or chart

- Position options available:

- Latest position

- Last known/communicated position

- 1 to 24 hour period

- Archive Files

- Supports the following services:

- GPS Lat'Long, course \& velocity

- Time and date sent

- Time and date received

- Sensor status reports

- Forms filing

- Fuel management data

- Trip record data

\section{Cartographic Flexibility}

- Display of numerous vector based maps

- Zoom up to $7 X$ for detail

- Allow any digital or hard copy map to be used as background map

- Maps are in multiple overlays

- User editable overlay

- Receives electronic file update

\section{Variable Communications Interface}

Basic map engine receives packets from many types of communications networks

\section{Stand Alone Configuration}

The program is complete within itself and optimized to run in a stand-alone configuration

\section{Front-End Communications Processor for Midrange and Mainframe}

For those applications where the newly received message and position information is useful in another computer which is running an operations package. The program is designed to prepare the data for transfer to these other systems and to serve as a front-end communications processor for them. This can be accomplished in a direct connection to the other computer or via a network

\section{Back-End Cartographic Terminal for Midrange and Mainframe}

For those applications where the new dynamic data is received by the operations package in an existing computer, the program can very nicely receive the position information from the computer and display the positions on the electronic maps. This prevents the need for putting cartography on the host computer.

\section{Low Cost}

Perhaps the most cost-effective solution to vehicle tracking in the world. Plus built-in two-way communications and many other extras.

\section{Two-Way Communications}

- No additional programs are neces. sary to exchange messages with mobiles through the network

- All handshake and protocol conversion is automated

- Operates in batch or real time

\section{Map is Human Interface to Communications}

- Communications are originated by pointing at vehicle or selecting vehicle from list

- Exact destination transmitter ID is always input when vehicle is selected

- All log keeping is automated

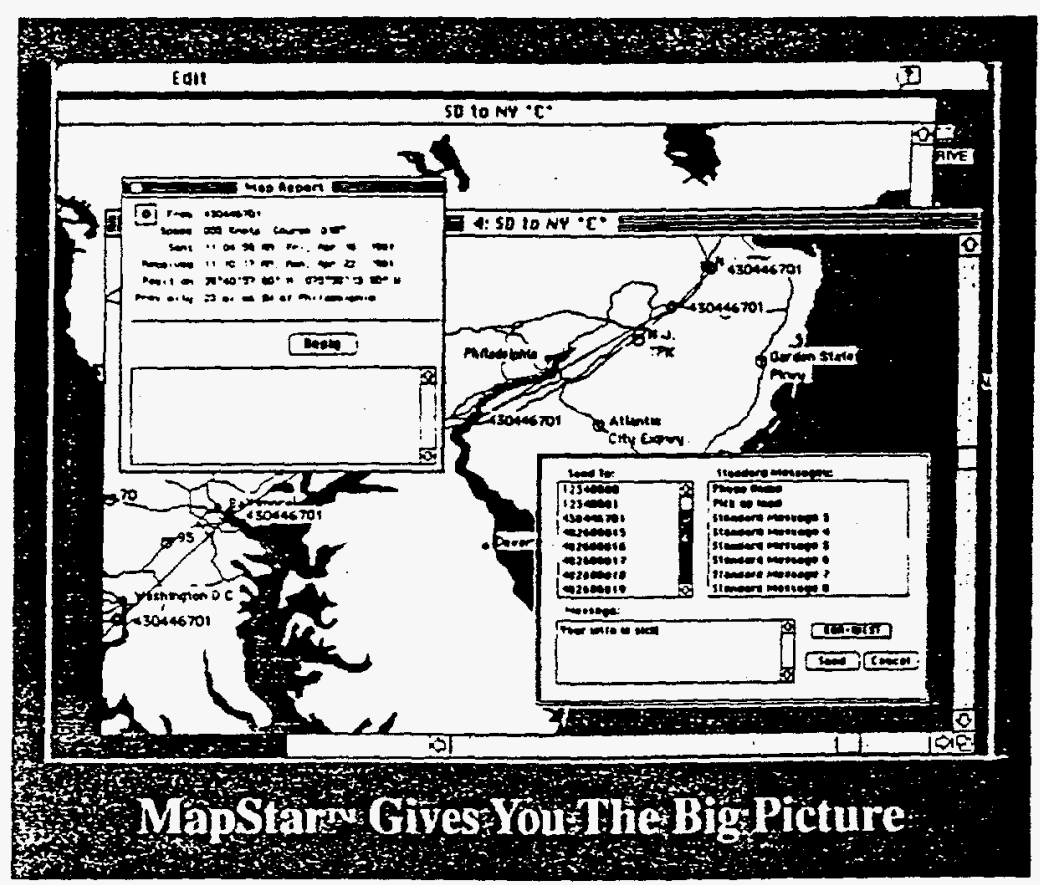


Friendly Operation

GUI-Geographical User Interface: the startlingly easy way to operate a complex and powerful computer. The ease of use and training saves even millions of dollars over time depending upon number of workstations and use.

\section{Network Management}

The optional TerraStar-Hub im routing, store-and-forward swilch gives carriers full network parameters and flexibility without compromising performance or cost effectiveness.

\section{Benefits of MapStar ${ }^{\mathrm{TM}}$}

The financial benefits of equipping a fleet with a Scientific-Atlanta MariStar ${ }^{\mathrm{TM}}$ or TerraStar ${ }^{\mathrm{TM}}$ terminal are varied depending upon the application. In a typical trucking application, benefits accrue to all interested parties.

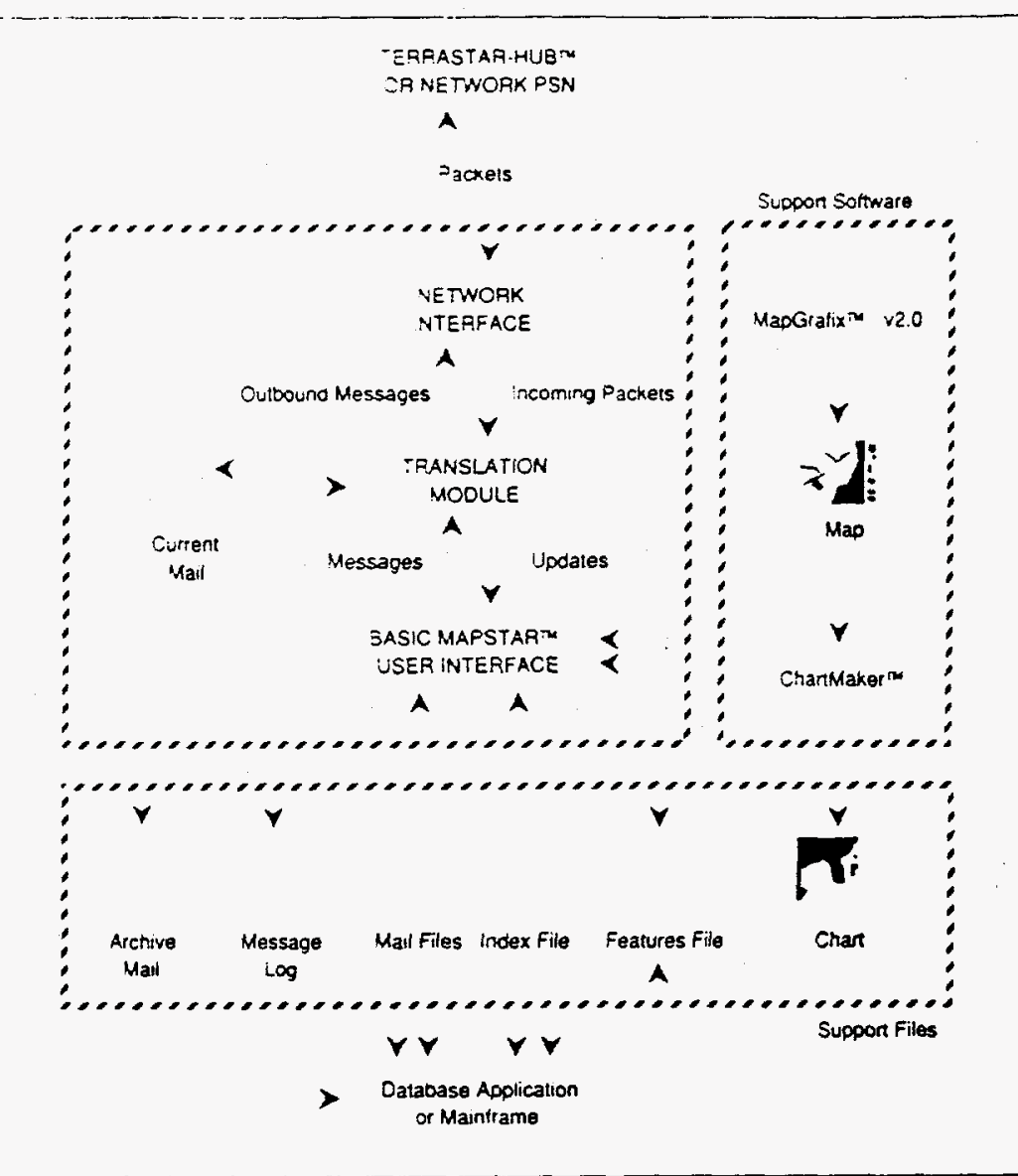

\section{The Trucking Company/Operator}

- Cost savings lead to a payback of less than one year

- More revenue mile per truck

- Decreased and predictable telecommunications cost

- Decreased out of route and deadhead miles

- MapStar ${ }^{\mathrm{TM}}$ is a marketing tool

- Offers a competitive edge

- A proactive rather than reactive customer service plan

- Improves management reporting capabilities

- Reduces accidents and lowers fuel consumption

- Reduces insurance premiums by $7-15 \%$

\section{The Driver}

- Near real-time communication between the driver and the dispatcher is accomplished easily from any location

- Quicker transit times

- With the optional Mobile MapStarm interface the driver can see his location at all times. The software gives a numeric latitude/longitude indication of current position. Vectorized maps are also available for the vehicle with a suitable display device

- Increases number of loads and revenue miles

- Emergency assistance is always available

- Eliminates filling out complex driver logs

MariStar and TertaStar are registered trademarks of Scientific-Allanta. MapStar is a registered trademark of ComGraphix. Incorporated. 


\section{The Shipper}

- Greater degree of Quality Control

- Increases control of high-value consignments

- Precise status and shipment information

- Accurate delivery time with position reporting. Tighter ETAs can result in Just-In-Time service to customers

- Rapid response to customer request and/or order. In-transit redirects and expedited deliveries are easy to effect

- Coordinate operations with shipping personnel to maximize efficiencies and productivity

\section{System Hardware Requirements}

MapStaris is designed to operate with the following system hardware:

- Scientific.Atlanta MariStarim or TerraStarim Inmarsat Standard-C andior -M Terminals

- Apple Computer, Inc. Macintosh ${ }^{\mathrm{TM}}$ systems, including Macintosh II, $\|x\| c x,,\|c i\| f$,$x , and$ Quadra 700 and 950 computers, using System 6.0 .5 or greater

- Any telecommunications network equipment that is able to connect to the specified Inmarsat Land or Coastal Earth Station

- Optional TerraStar-Hubin for use in multiple dispatcher networks.

Throughout the world, shippers can rely on Scientific-Allanta's AVL and Inmarsat systems expertise. After providing the first Inmarsat coastal earth stations, and more than 3,000 Irmarsat terminals, the transport industry has come to rely on ScientificAtlanta since 1976 to provide mobile communications solutions woridwide.

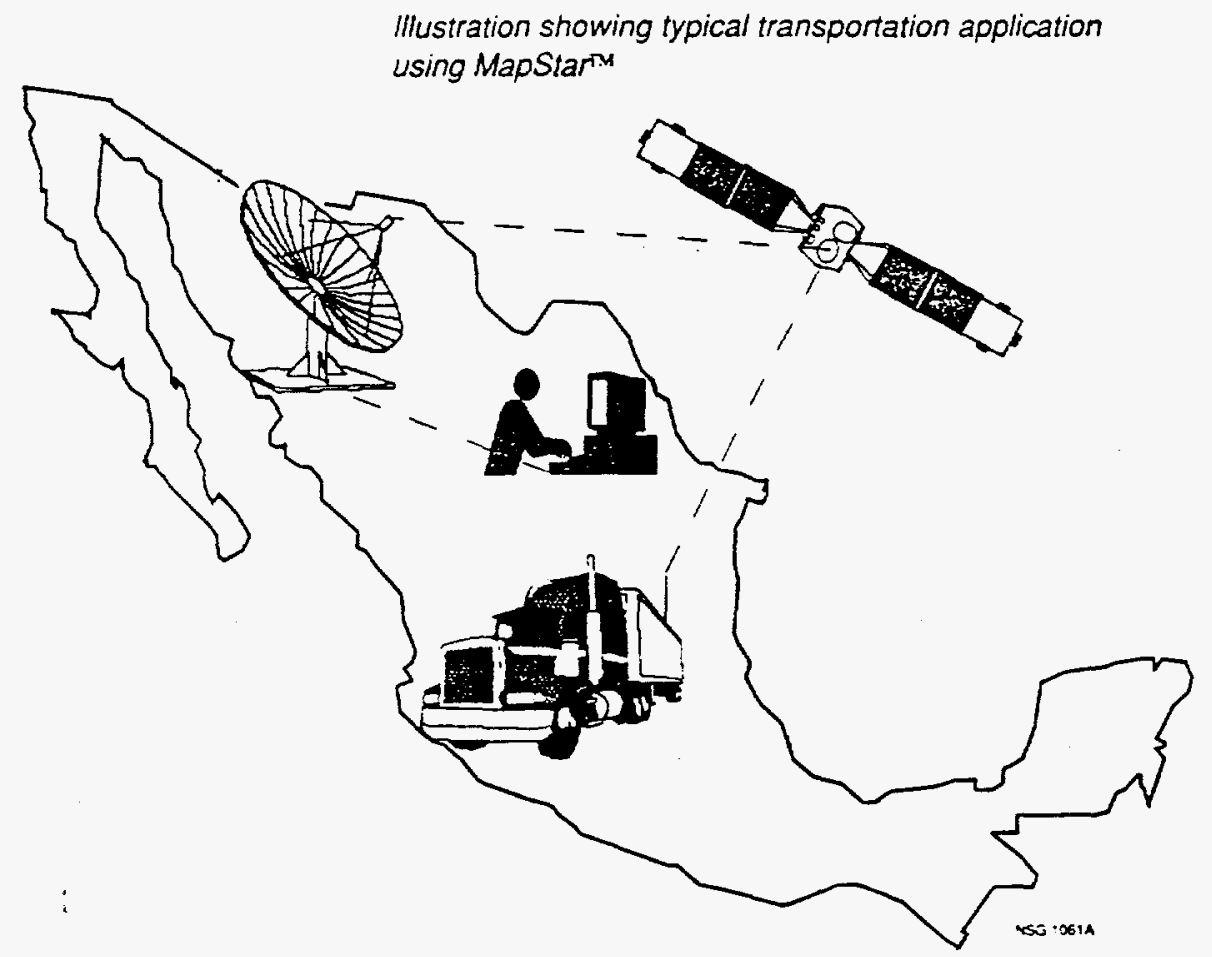

Scientific-Atlanta, Inc.

Our customers are the winners.

United States: 4291 Communications Drive. Norcross. GA 30093: Telephone: (404) 903-6001: Telex 4611804 Canada: 120 Middlefield Road. Scarborough. Ontario M1S 4M6. Canada: Telephone: (416) 290.6888: Telex 06525344 United Kingdom: Home Park Estate. Kings Lanoley Hers. WD4 8LZ England: Telephone: Kings Langley 44.923-266133: Telex 912044 Australia: Unit 2.2 Aquatic Drive. Frenchs Forest. N.S.W. 2086. Australia: Telephone: (612) 452-3388: Fax: (612) 451-4432; Telex 790 177418 France: 4 Avenue Gabriel Peri. 78360 Montesson France: Telephone: 33-13-976-9191: Telex 896385 Haly: Via Benedeno Croce. 19. 00142. Rome. Italy: Telephone: 39-6-5409994: Telex 621441

Germany: Albert-Schwetzer-Strasse 66. 8000 Muencren 83. Postfach 830935 Germany; Telephone: 49-89-6780010: Telex 5212264 